The University of North Carolina at Greensboro

JACKSON LIBRARY

$C Q$

no. 1296

UNIVERSITY ARCHIVES 
Mander, Anthony Michael. Third Party Instigation of Aggression as a Function of Noncooperation and "Veto Power." (1975) Directed by: Dr. Jacquelyn W. Gaebelein Pp. 96.

Previous research has identified several important variables as determinants of instigative aggression. While provocation from a victim has been found to reliably eicit increased attack from an instigator, refusal on the part of an aggressor to comply with suggested attack has been found to deter the amount of instigated aggression. Two plausible hypotheses have been offered to explain the deterring effects of aggressor noncooperation upon instigative aggression. A conformity hypothesis suggests that instigators conform to a nonm not to hurt modeled by the noncooperative aggressor. Actual internalization of the altruistic norm may occur, or it ray not occur in which case mere compliance to the norm results. A power hypothesis, on the other hand, suggests that instigators reduce their level of attack in orden to maintain. a sense of control in the experimental situation.

The purpose of the present study was to test the valjaity of these two alternative hypotheses. A modification of Gaebeiein's (1973a) reaction time procedure was employed such that half of the subjects (serving in the role of instigator) were allowed to "veto" the shock selection of a confederate aggressor. In addition, half of the subjects were paired with an aggressor who was instructed to cooperate with the instigator (i.e., deliver the suggested shock) and 
half of the subjects were paired with a noncooperative aggressor (i.e., one who was instructed to refuse to set high levels of shcok). Fourty-five female subjects were randomly assigned to one of the following four experimental conditions: cooperation-no veto, cooperation-veto, noncooperation-no veto and noncooperation-veto. The experiment proceeded in two parts. During Part 1 , the subject acted. as instigator, i.e. she suggested shock levels for the aggressor to set. During Part 2, the subject became more directly involved in the aggressive interaction by virtue of the fact that she was instructed to set the shock buttons herseif.

The results of Part 1 tended to support the power hypothesis in that subjects in the noncooperation-veto group demonstrated an elevation in suggested shock when compared to noncooperation-no veto subjects. The difference was of marginal significance, however; and the results of Part 2 did not offer support for the power hypothesis. An examination of individual. subjects' data within groups indicated three clearly distinquishable patterns of response within the noncooperationveto group. These three patterns corresponded to the predictions of the conformity, complaince and power hypotheses. Questionnaire responses given by subjects in the noncooperationveto group were found to be commensurate vith the particular behavioral pattern exhibited. It was conciuded that the 
hypotheses of power, conformity and compliance are all viable and that in the present investigation, all were operating with different individuals. 


\section{THIRD PARTY INSTIGATION OF AGGRESSION AS A FUNCTION OF NONCOOPERATION AND "VETO POWER"}

$$
\text { by }
$$

Anthony Michael Mander

A Thesis Submitted to the Faculty of the Graduate School at The University of North Carolina at Greensboro in Partial Fulfillment of the Requirements for the Degree Master of Arts

\section{Greensboro \\ 1975}

Approved by

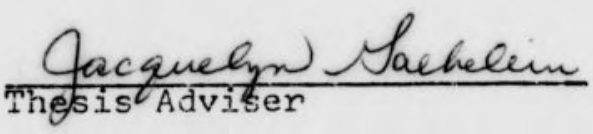




\section{APPROVAL PAGE}

This thesis has been approved by the following committee of the Faculty of the Graduate School at the University of North Carolina at Greensboro.

Thesis Adviser Gacguebr Mablein

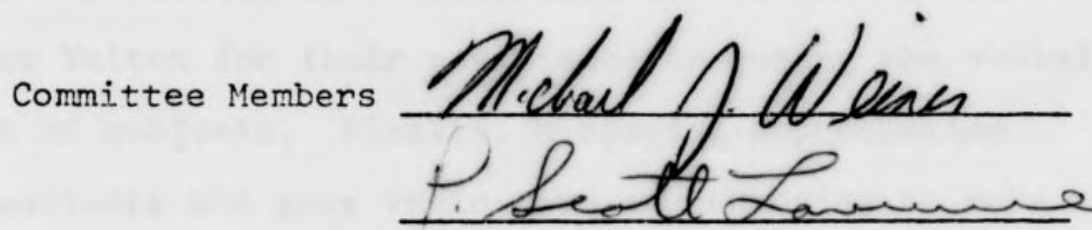

$\frac{4-21-75}{\text { Date of Acceptance by Committee }}$ 


\section{ACKNOWLEDGMENTS}

The author wishes to extend special thanks to Dr. Jacquelyn W. Gaebelein for her valuable guidance and encouragement during the many phases of this research, project. Appreciation is also extended to Dr. Michael Weiner and to Dr. P. Scott Lawrence for their helpful criticisms and comments on the preliminary proposal and on a previous draft of this manuscript. Thanks go also to Jean Bambarger, Fran Massa, Betty Self and Margaret Mortimor for serving as confederates and to Ann Yelton and Bruce Yelton for their assistance in rating the verbal comments of subjects. Finally, a special appreciation to the subjects who gave their time and energies to make this research possible. 
ACKNOWLEDGEMENTS ......................... . . . .

LIST OF TABLES ................. . . . v

LIST OF FIGURES ................... vi

CHAPTER

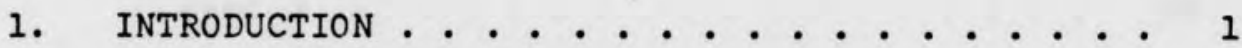

Instigator Characteristics . . . . . . . . 3

Aggressor Characteristics. . . . . . . . . 4

Victim Characteristics.......... 6

Extrinsic Rewards. . . . . . . . . . 7

Statement of the Problem . . . . . . . . 7

2. METHOD ......................... 18

Subjects . . . . . . ........ 18

Apparatus. . . . . . . . .... 18

Procedure. . . . . . . . . . . . . 19

Sessions . . . . . . . . . . . . . 21

Experimental Design. . . . . . . . . 23

3. RESULTS. . . . . . . . . . . . 29

Shock Intensity Suggested (Part 1) . . . . . 29

Change from Part 1 to Part 2........ 32

Shock Intensity Set (Part 2) . . . . . . . 33

Questionnaire Responses. . . . . . . . . 35

verbal Comments. . . . . . . . . . 40

4. DISCUSSION ............ 43

BIBLIOGRAPHY ............... 58

APPENDIX .......................... 60 


\section{LIST OF TABLES}

TABLE

PAGE

1 Experimental Design

Part 1............... . 24

Part 2................ 25 


\section{LIST OF FIGURES}

FIGURE

PAGE

1 Mean Shock Intensities Suggested During Part 1 as a Function of Cooperation, Veto and Trial Blocks. . . . . . . . . . 30

2 Shock Intensities for Part 1 and Part 2 for Noncooperation-veto Subjects as a Function of Trial Blocks... . . . . . . . . . 49

3 Shock Intensities for Part 1 and Part 2 for Cooperation-veto Subjects as a Function of Trial Blocks............... 50

4 Shock Intensities for Part 1 and Part 2 for Cooperation-no veto Subjects as a Function of Trial Blocks. . . . . . . . . . . . .

5 Shock Intensities for Part 1 and Part 2 for Noncooperation-no veto Subjects as a Function of Trial Blocks. 


\section{CHAPTER 1}

\section{INTRODUCTION}

In an experimental study of obediance, Milgram (1965) instructed subjects to deliver electric shocks to another person. Subjects, acting as teachers, were instructed to deliver a shock to a learner (confederate) each time he committed an error on a paired associate learning task. Thirty levels of shock, ranging from "Slight Shock" to "Danger: Severe Shock" were provided and teachers were instructed to increase the level of shock each time the learner responded incorrectly. Milgram was interested in determining the point at which subjects would refuse to deliver further shock. In spite of strong protests from the learner, $65 \%$ of the subjects continued to participate in the experiment until they had delivered the highest shock. In a postscript to his article, Milgram stated:

"With numbing regularity good people were seen to knuckle under the demands of authority and perform actions that were callous and severe. Men who are in everyday life responsible and decent were seduced by the trappings of authority, by the control of their perceptions, and by the uncritical acceptance of the experimenter's definition of the situation, into performing harsh acts (1965, p. 74)."

Similariy, Borden and Taylor (1973) have demonstrated the effects of social pressure upon the aggressive behavior of 
subjects. Utilizing a reaction time paradigm developed by Taylor (1967) the authors illustrated that subjects could be persuaded (by three confederate observers) to either increase shock delivered to a non-aggressive opponent or to decrease shock delivered to an aggressive opponent.

Milgram (1965) has noted that social aggression often involves a triad, i.e. an authority, an executant and a , victim. Such a triad was clearly visable in the Milgram and Borden and Taylor studies, and was reflective of aggression as it often occurs in the real world (CF. Gaebelein, 1973a).

In a discussion of the instigator--aggressor--victim triad, Gaebelein (1973a) has noted that three relationships may be targeted for study. The relationship between the aggressor and the victim has been most widely investigated (Berkowitz, 1962; Buss, 1963; and Taylor, 1973). The instigatorvictim relationship is an indirect one and has received little experimental attention. The third relationship, i.e., instigator-aggressor, has been studied by Milgram and by Borden and Taylor from the standpoint of the aggressor's compliance to the instigator. Gaebelein (1973a), on the other hand, has turned her attention to the variables which influence the instigator's behavior and has devised a laboratory procedure in which thind party instigation of aggression can be systematically investigated. In this procedure, the subject, assigned the role of instigator, and a confederate, acting as aggressor, supposedly compete with another pair of subjects in a reaction 
time task. The subject is told that the responder (confederate aggressor) is competing with an opponent, situated in another room. According to the instructions, the slower responder on any given trial supposedly receives one of five levels of shock, the particular level being chosen by the opponents. In actuality, there are no opponents and the percentage of wins and loses, as well as the opponent shock settings, are determined by the experimenter. The subject is informed that his task is to advise the responder as to what shock level to set for the opponent. The subject's role as advisor is explained as an attempt to free the responder from all demands except for his major responsibility, i.e., having the fastest reaction time possible. In this situation, instigative aggression is operationally defined as the level of shock suggested by the advisor.

Using this procedure, a number of variables have been studied. These variables may be categorized as instigator characteristics, aggressor characteristics, victim characteristics, and extrinisic rewards.

\section{Instigator Characteristics}

Several predispositional variables were found to have no effect upon the intensity of shocks suggested by the advisor. Gaebelein (1973a) reported no differences in instigative aggression between high and low Machiavellian males. Similarly, Gaebelein (1974) found no significant correlations between the 
intensity of shock suggested by females and their scores on the Buss-Durkee Hostility Inventory, the Marlowe-Crown Social Desirability Scale or the Machiavellianism Scale.

On the other hand, several situationally-induced instigator variables have been shown to affect the degree of aggression a subject will instigate. Gaebelein and Hay (1974) found that advisors who were vulnerable, i.e. received a shock when their responders did, suggested significantly less intense shocks than did nonvulnerable subjects. In addition, subjects who were the target for attempted attacks from the opposition advisor were significantly more instigative than subjects who were not attacked.

Gaebelein and Mander (1974) conducted two studies which examined the effects of the subjects role as either aggressor or advisor upon the intensity of shock directed against a victim. The results of these studies indicated that when the victim was nonprovocative, subjects delivered significantly more intense shocks as advisors than as aggressors. When the victim was provocative, however, no significant differences in shock intensity were obtained as a function of roles.

\section{Aggressor Characteristics}

Several studies have manipulated the characteristics of the aggressor by instructing confederates to be either cooperative, i.e. set the shock level suggested by the subject, 
or noncooperative, i.e. refuse to set anything higher than level two shocks. Gaebelein (1973a, 1973b) found that subjects who were paired with noncooperative confederate responders suggested significantly lower shock settings than subjects who were paired with cooperative responders, even though the level of attack from the opponent increased over trials.

In another study, Gaebelein and Hay (1975) studied the separate effects of verbal and behavioral noncooperation on the instigation of aggression. Subjects in this study were randomly assigned to one of four groups. In a verbal cooperation-behavioral cooperation group, a confederate responder demonstrated both verbal and behavioral agreement to the suggested shock levels. Confederates in a verbal cooperative-behavioral noncooperative group gave verbal approval of advised shock levels of 3 or greater but would only set shock levels of 1 or 2 . In a third condition, verbal noncooperation-behavioral cooperation, confederates set shock levels of 3 or greater when advised, but expressed verbal disapproval of the shock intensity. Finally, responders in a verbal noncooperation-behavioral noncooperation condition verbally disapproved of shock settings of 3 or greater, and furthermore, refused to set shock levels greater than 2 .

The results of this investigation reaffirmed the cooperation-noncooperation phenomenon. That is, the mean shock settings for verbal cooperation-behavioral cooperation 
subjects was significantly higher than the mean shock settings for the other three groups, with subjects in the verbal noncooperation-behavioral noncooperation group suggesting the lowest mean shock levels. Both verbal and behavioral noncooperation were effective in reducing the level of suggested shock with motor noncooperation appearing to be somewhat more effective. The attenuation in instigative aggression was striking for subjects in the verbal noncooperation-behavioral cooperation, verbal cooperation-behavioral noncooperation and verbal noncooperation-behavioral noncooperation conditions (the mean shock settings for these groups were not significantly different from each other).

Victim Characteristics

Victim characteristics have been manipulated by altering the feedback subjects receive concerning the level of shock the opponents had ostensibly intended for them.

Gaebelein (1973a, 1973b) and Gaebelein and Hay (1974, 1975) have demonstrated that increasing provocation from the victim (i.e. increasing shock intensities) results in increased instigative aggression from the advisor. Gaebelein and Hay (1974) manipulated both instigative aggression (shock directed toward the responder) and direct aggression (shock directed toward the advisor). In this study, subjects were told that they could decide whether or not the opposition advisor should also receive a shock if their responder lost the reaction time trial. Likewise, they were told that they would be subject to shock from their opponent's advisor. The results of this study 
indicated that subjects who were actually attacked both instigated more aggression and more frequently set shock for the opposition advisor.

\section{Extrinsic Rewards}

Two studies have examined the effects of instrumental reward upon instigative aggression (Gaebelein, 1973a, 1973b). Subjects in these studies were paid 1 cent for setting a level 1 shock, 2 cents for a 2 shock, 3 cents for a 3 shock, 4 cents for a 4 shock and 5 cents for a 5 shock. Results indicated that reward elevated the intensity of shock suggested by males (Gaebelein, 1973a), but had no effect for females (Gaebelein, 1973b).

\section{Statement of the Problem}

As a result of the research conducted thus far, several variables have been identified as powerful determinants of instigative aggression. On the one hand, provocation was shown to be a reliable antecedent to instigative aggression, while noncooperation, on the other hand, was found to be a potent deterrent. The attenuating effects of noncooperation were observed even when the countervailing variable of provocation was present.

Several explanations of the noncooperation phenomenon have been postulated. One possibility is that subjects simply gave up out of apathy or that their behavior extinquished over trials. An examination of verbal comments made by subjects 
during these experiments has revealed, however, that the verbal behavior of subjects in the noncooperation conditions was actually more instigative than that of subjects in the cooperation conditions (Gaebelein, 1973a, 1973b; Gaebelein and Hay, 1975).

Two other theoretical hypotheses have been offered as alternative explanations of the data (Gaebelein, 1973a): One hypothesis concerns the possibility that subjects conformed to a norm of non-aggression modeled by the noncooperative responder. On a post-experimental questionnaire, however, most noncooperative subjects rated the responder as less desirable and the situation as less pleasant than did cooperative subjects. The author stated that "If $\underline{S}$ in the present study instigated less aggression out of a desire not to hurt, they should feel virtuous and this should be reflected in their perception of the responder (Gaebelein, 1971, p.74)." It was concluded, therefore, that post-experimental questionnaire data was not commensurate with a norm hypothesis. It should be noted that this interpretation assumed an internalization of the norm not to hurt. Gaebelein did not make a distinction between conformity and compliance, the latter being an overt behavior change in the direction of the norm, not necessarily accompanied by private acceptance (Kiesler \& Kiesler, 1969). Thus, although her data may not follow from a conformity hypothesis, it may be explained from the standpoint of a norm of compliance. 
Finally, a power hypothesis was offered as a possible explanation of the data. That is, subjects who did not have their advice heeded may have begun to feel powerless. The only way subjects could have regained at least a sense of power in the experimental situation would have been to suggest the shock levels that the responder was willing to set ( 1 's and 2 's). This hypothesis is consistent with theories of social power and social inequity, i.e. modifications in behavior may occur in an attempt to regain control, accompanied by devaluation of the usurper of power (Shopler, 1965; Adams, 1965).

However, Gaebelein and Hay (1975) noted that, since the suggestions of subjects in the verbal noncooperationbehavioral cooperation condition were carried out by the confederates, these subjects probably did not experience a "loss of power". Nevertheless, an attenuation of instigated agression was apparent for this group. Post-experimental questionnaire data revealed that only three of the 10 verbal noncooperation-behavioral cooperation subjects admitted that they were influenced by the responder's verbal desire not to hurt. Five of the remaining seven verbal noncooperationbehavioral cooperation subjects described their strategy as an altruistic one. In comparison, seven verbal noncooperationbehavioral noncooperation subjects admitted that they were influenced by the responder's altruistic comments and none subscribed to an altruistic strategy. Only four verbal cooperation-behavioral noncooperation subjects described their strategy 
as altruistic. Gaebelein and Hay suggested that the verbal noncooperation-behavioral cooperation condition may have led to a greater internalization of an altruistic norm than did the other conditions.

As pointed out previously, if such an internalization did in fact occur, this should be reflected in the subjects' ratings of the responder. That is, internalization should result in more favorable ratings of the responder by verbal noncooperation behavioral cooperation subjects as compared to ratings given by subjects in the other three groups. An analysis of responder ratings, however, indicated significant differences only on two of 31 attributes. The verbal noncooperation-behavioral cooperation responders were rated as smaller and more feminine as compared to verbal cooperationbehavioral noncooperation responders, while no significant differences between groups were found for ratings such as aggressiveness, competitiveness and revengefulness.

Internalization of an altruistic norm should also result in differences in the kinds of verbal comments made by subjects during the course of the experiment. All such comments were recorded and subsequently rated independently by two persons as falling into one of four categories: agressive comments, comments of pacificism, comments of concern for the responder and miscellaneous comments. The norm hypothesis would predict that verbal noncooperation-behavioral 
cooperation subjects would make aggressive comments less often and make comments of concern and pacificism more often than subjects in the other three groups. Results of analyses performed on the ratings of comments revealed no significant mean differences between groups for aggressive comments or comments of pacificism. With regard to the aggressive comments, the actual means obtained tended to support the power hypothesis rather than the norm hypothesis. That is, subjects in the verbal cooperation-behavioral noncooperation, verbal noncooperation-behavioral cooperation and verbal noncooperation behavioral noncooperation groups made a greater percentage of aggressive comments $(\underline{M}=22 \%, 24 \%$, and $22 \%$, respectively) than did subjects in the verbal cooperationbehavioral cooperation group $(\underline{M}=8 \%)$. An analysis of the frequency of concern comments indicated that verbal cooperationbehavioral cooperation subjects more frequently made comments of concern than did verbal noncooperation-behavioral cooperation or verbal cooperation-behavioral noncooperation subjects. Once again, these findings are inconsistent with an internalization of norm hypothesis.

An alternative explanation to the norm hypothesis which is consistent with the original power hypothesis may be offered to explain the reduction in instigative aggression in the verbal noncooperation-behavioral cooperation group. That is, verbal noncooperation may have been perceived as a potential cue for behavioral noncooperation. Subjects may have reduced their shock settings following verbal disapproval in anticipation 
cooperation subjects would make aggressive comments less often and make comments of concern and pacificism more often than subjects in the other three groups. Results of analyses performed on the ratings of comments revealed no significant mean differences between groups for aggressive comments or comments of pacificism. With regard to the aggressive comments, the actual means obtained tended to support the power hypothesis rather than the norm hypothesis. That is, subjects in the verbal cooperation-behavioral noncooperation, verbal noncooperation-behavioral cooperation and verbal noncooperation behavioral noncooperation groups made a greater percentage of aggressive comments $(\underline{M}=22 \%, 24 \%$, and $22 \%$, respectively) than did subjects in the verbal cooperationbehavioral cooperation group $(\underline{M}=8 \%)$. An analysis of the frequency of concern comments indicated that verbal cooperationbehavioral cooperation subjects more frequently made comments of concern than did verbal noncooperation-behavioral cooperation or verbal cooperation-behavioral noncooperation subjects. Once again, these findings are inconsistent with an internalization of norm hypothesis.

Ar alternative explanation to the norm hypothesis which is consistent with the original power hypothesis may be offered to explain the reduction in instigative aggression in the verbal noncooperation-behavioral cooperation group. That is, verbal noncooperation may have been perceived as a potential cue for behavioral noncooperation. Subjects may have reduced their shock settings following verbal disapproval in anticipation 
of behavioral noncooperation -- a situation in which loss of power would have been experienced.

To summarize, two plausible hypotheses have been offered to explain the phenomenon of reduced instigative aggression in a situation of aggressor noncooperation. The norm hypothesis states that the instigator models or conforms to an altruistic norm set by the responder; actual internalization of the norm may occur, or it may not occur in which case mere complaince to the norm would result. The power hypothesis views the effect as an attempt, on the part of the instigator, to maintain a sense of control over the experimental situation. In view of the lack of supporting evidence for the norm hypothesis, particularly when internalization is predicted, the power hypothesis seems the more viable of the two. Although the available data seems to support the power hypothesis, previous research has not clearly tested the validity of these two alternative hypotheses. The purpose of the present sutdy was to permit such a test by giving subjects the option to overrule the responder's shock selection. Briefly, Gaebelein's (1973a) procedure was modified such that half of the subjects in the experiment were allowed to "veto" a confederate's shock selection. These subjects were given the final say as to the level of shock delivered to the opponent. In addition, half of the subjects were paired with a cooperative confederate, and half with a noncooperative confederate. 
The factors, veto and cooperation, were crossed resulting in the following four experimental conditions: noncooperation-no veto, noncooperation-veto, cooperationno veto, and cooperation-veto. The noncooperation-no veto group represents a replication of Gaebelein's (1973a, 1973b) noncooperation group and Gaebelein and Hay's (1975) verbal noncooperation-behavioral noncooperation group. For subjects in this group, confederates refused to set a shock of 3 or greater and subjects were not given the opportunity to overrule this decision. Confederate responders in the noncooperation-veto group refused to set a shock of 3 or greater on an initial trial, but complied with the advisor on a "correction trial." Subjects in the noncooperationveto group were given the opportunity to employ an "error correction system" (described below) as a means of maintaining power over the responder. According to the power hypothesis, subjects in this group should demonstrate a higher level of suggested shock as compared to subjects in the noncooperationno veto group. In particular, they should exercise their power over noncooperation from the responder by vetoing the responder's shock-settings and suggesting a higher shock. The conformity hypothesis, on the other hand, would predict an attenuation in suggested shock settings similar to an attenuation demonstrated by noncooperation-no veto subjects, in spite of the fact that noncooperation-veto subjects had the power to 
determine that the opponent actually receive the shock of their choice. Congruent with Gaebelein's (1973a, 1973b) and Gaebelein and Hay's (1975) findings, subjects in the cooperation-no veto group should demonstrate an increase in suggested shock levels, as compared with noncooperation-no veto subjects, as a function of increasing provocation from the opponent. The cooperation-veto group was included as a control for the presence of an "error control panel" (described below). That is, subjects might have increased or decreased their level of advised shock as a function of the increased opportunity to "change their minds" as to which shock level to advise.

The experiment proceeded in two parts. During Part 1, the subject acted as instigator, i.e. she suggested shock settings for the responder to set. The discussion above has concerned itself with the possible outcomes for Part 1 of the experiment.

During Part 2 of the experimental session, the subject became more directly involved in the aggressive interaction by virtue of the fact that she was instructed to set the shock buttons herself. Part 2 provided an additional test of the power versus conformity hypothesis. According to the conformity hypothesis, no change in mean shock setting in any of the four groups from Part 1 to Part 2 should result. Subjects in the cooperative groups should advise high shocks (regardless of the veto-no veto manipulation) during Part 1 and should set high 
shocks during Part 2. Subjects in the noncooperative groups should advise low shocks during Part I (relative to the cooperative groups) and should set low shocks during Part 2 because they will have conformed to a norm of low aggressiveness. If internalization accompanies conformity, not only should low shock settings be established during Part 1 and maintained throughout Part 2 (for noncooperative subjects), but the subjects' ratings of the responder should also be more favorable and the verbal comments made by subjects during the experiment should contain less aggressive elements and reflect more concern for the responder. On the other hand, if internalization did not occur, that is if subjects complied with the responders' wishes without private acceptance of the norm, noncooperative subjects should denonstrate an increase in shock directed toward the opponent during Part 2 because explicit pressure to comply was removed.

In contrast, the power hypothesis would predict no change in shock settings for the cooperation-veto, cooperation-no veto and noncooperation-veto groups, but would predict an increase in shock settings for the noncooperation-no veto group during Part 2. According to the power hypothesis, subjects in the cooperation-veto, cooperation-no veto and noncooperationveto groups should advise high shock levels during Part 1, and set high shocks during Part 2. On the other hand, noncooperationno veto subjects should advise low shock settings during Part 1 , 
but with the acquisition of power (the opportunity to set levels themselves) should demonstrate an increase in shock levels during Part 2 .

The hypotheses tested were the following:

1) There will be no significant difference in advised shock settings between subjects in the veto groups and subjects in the no veto groups.

2) Advised shock settings will be significantly higher for subjects paired with cooperative responders than for subjects paired with noncooperative responders.

3) The level of advised shock will be significantly higher following lose trials, as compared to the advised shock ievel following win trials.

4) The level of advised shock will increase as a function of provocation from the opponent; i.e. there will be a significant. main effect for trial blocks.

5) The mean level of advised shock will differ as a function of the unique combinations of the levels of the between subject variables; i.e. noncooperation-veto subjects will suggest significantly higher shock intensities than noncooperation-no veto subjects.

6) The level of advised shock for subjects in the cooperation and noncooperation groups will increase differentially as a function of provocation from the opponent; i.e. cooperative subjects will suggest increasingly higher shock intensities as a function of provocation, whereas noncooperative subjects will not. 
7) The change in shock intensities directed toward the opponent from Part 1 to Part 2 will be commensurate with the power hypothesis. That is, only the noncooperation-no veto subjects will show a significant change. 


\section{CHAPTER 2}

\section{METHOD}

\section{Subjects}

Fourty-five female students were randomly selected from a subject pool at the University of North Carolina at Greensboro. Participation was in partial fullfillment of course requirements for undergraduate classes in introductory psychology.

\section{Apparatus}

The apparatus included a responder's task board, the experimenter's programming-monitoring equipment (described by Gaebelein, 1973a) and an advisor "error-panel".

The responder's task board was equipped with three instructional lights: two white lights labeled "set" and "press", respectively, and a third, amber light, labeled "release". A reaction time key was located below the instructional lights. The board was also equipped with five red feedback lights, labeled from one to five, and with one white light labeled "lose". The feedback lights provided information as to the outcome of each experimental trial. Finally, the task board included five shock-setting buttons numbered consecutively from one to five.

For half of the subjects, an "error-panel" was included and was supplied with two buttons labeled "restart" and "proceed". 
The error panel was part of an "error correction system" (described in detail below) and allowed a subject to maintain control over the responder's shock-setting behavior. The experimenter panel allowed for the monitoring of which shock button the responder set on each trial, and whether the advisor pushed the "restart" or the "proceed" button. In addition, the panel permitted control over the sequence of lights which flashed on the responder's task board.

An intercom system allowed for the monitoring of shock-settings suggested by the advisor, and provided a means of communication between experimenter and subject.

Shocks were delivered through a concentric shock electrode (Tursky, Watson, and O'Connell, 1965) via an AC constant current electrostimulator.

\section{Procedure}

Two persons, the subject and a female confederate, were brought into the experimental room and told that they would be competing in a reaction time task with two other female subjects, situated in another room. At this point, subjects were informed that the study involved electric shock. The experimenter explained that, although the procedure was completely safe and harmless, anyone who was unwilling to continue could withdraw from the experiment at that time. One subject withdrew from the experiment because of an unwillingness to deliver shock to others. 
If the subject agreed to continue, the experimenter explained that one subject of each pair would be a "responder" and the other an "advisor". The subject and the confederate were each asked to select one of two slips of paper in order to randomly determine which role they would play. Actually, both slips of paper said "advisor" but the confederate reported that her's read "responder". Thus, the real subjèct always acted as advisor, and the confederate as responder.

The confederate was seated in front of the task board and an inoperative shock electrode was connected to the palmer side of her left wrist. The subject was seated adjacent to the responder, and an operative electrode was attached to her left wrist.

The experimenter played a set of taped instructions describing the procedure which was employed to determine the subject's pain threshold for shock (see Appendix A for complete instructions). Using a modified method of limits an "unpleasantness" threshold was determined, first for the subject and then a mock procedure was carried out for the responder. The responder actually received no shock, but acted as though she did, reporting as "definitely unpleasant" a shock intensity approximately equal to the intensity judged "definitely unpleasant" by the subject.

Following the completion of the shock threshold procedure, the shock electrode was removed from the advisor's wrist. It was explained to the subject that, as advisor, she would not 
be receiving shocks during the experiment. She was informed that she was subjected to the shock threshold procedure so that she would know that the responder would be experiencing during the experiment.

\section{Sessions}

The experimental session proceeded in two parts. During Part 1, the subject acted as instigator; i.e. she suggested shock levels for the responder to set. During Part 2, the subject became more directly involved in the aggressive interaction by virtue of the fact that she was instructed to set the shock buttons herself, although the responder was still present and competing in the reaction time competition.

Part 1. A set of taped instructions was played describing the experimental task to be performed (see Appendix B). Briefly, each trial in the task involved four events: 1) The "set" light flashed at which time the subject suggested to the responder the shock level to set for the opponent, should she lose on the coming trial. Subjects were told that the purpose of their role as advisor was to relieve the responder of the burden of deciding what shock button to set, so that she could concentrate only on having the fastest reaction time possible. After the advisor suggested a shock setting, the responder pressed one of the five shock buttons. For subjects in the veto conditions, the advisor pressed either the "restart" or the "proceed" button on the error panel. When the "proceed" button 
was pushed, the trial continued. If, however, the advisor pushed the "restart" button, the trial was interrupted, the advisor re-advised the responder, and then the trial continued (see discussion below). Subjects in the no veto conditions were instructed to press the proceed button on each trial after the responder had set one of the shock buttons. 2) The "press" light flashed at which time the responder depressed the reaction time key. 3) The "release" light flashed and the responder removed her finger from the reaction time key as fast as possible. 4) One of the five "feedback" lights flashed, indicating which shock level the opponent had ostensibly set for the responder. Subjects were told that the number 5 shock was equal to the shock the responder judged most unpleasant during the threshold procedure and that the other shocks were percentages of this. If the trial was pre-determined to be a lose trial, the lose light flashed, and the responder feigned a shock of the intensity set by the opponent.

The interval between the set and press lights was 10 seconds, the interval between the other components of the trial was 8 seconds. The intertrial interval was 10 seconds.

Part 2. The experiment continued as described above for 25 trials. At the end of this time the experimenter played the following recorded instructions:

In the last portion of this experiment we are going to try to decrease the responder's reaction times even further. We are going to try to accomplish this by removing one more distraction from the responder's task. Because pushing the shock buttons may prevent the responder from concentrating fully on having the fastest reaction time possible, for the 
remainder of the experiment, both advisors are to set the shock buttons for their responders. That is, when the set light flashes, rather than suggest a shock level for the opponent, the advisors are to lean over and set the shock levels they wish the opponent to receive should the opponent lose on the coming trial.

Following the above instructions, the experiment proceeded as before for 13 additional trials.

At the end of the experimental session, subjects were asked to complete a questionnaire (Appendix C). Advisors rated themselves and the responders on a six-point scale for 31 attributes, and several questions concerning the strategy employed by the subject were also answered.

\section{Experimental Design}

The experimental conditions were defined by two between subject variables, cooperation and veto, and by two within subject variables, provocation and winning. The design is schematized in Table 1.

Cooperation. Half of the subjects in the experiment were paired with a cooperative partner, and the other half with a noncooperative partner. Cooperative confederates set the advised shock level on each trial.

Noncooperative confederates set the suggested shock levels only when the recommended settings were 1 's and 2 's. If the subject advised a shock of 3 or greater, the confederate stated, "I don't believe in shocking people", and set a 1 or a 2 (confederates were told to randomly set an equal number of $I^{\prime}$ 's and $\left.2^{\prime} \mathrm{s}\right)$. In order to keep verbal interaction in the noncooperative groups to a minimum, the noncocperative confederates 
TABLE 1

Part 1

\begin{tabular}{|l|c|c|c|c|}
\hline & Trial Block & Trial Block & Trial Block & Trial Block \\
\hline Cooperation & Win Lose & Win Lose & Win Lose & Win Lose \\
\hline Veto & & & & \\
\hline No Veto & & & & \\
\hline Non-Cooperation & & & & \\
\hline Veto & & & & \\
\hline No Veto & & & & \\
\hline
\end{tabular}


TABLE I (Cont.)

Part 2

\begin{tabular}{|l|c|c|}
\hline & Trial Block & Trial Block \\
\hline Cooperation & Win Lose & Win Lose \\
\hline Veto & & \\
\hline No Veto & & \\
\hline \hline Non-Cooperation & & \\
\hline Veto & & \\
\hline No Veto & & \\
\hline \hline
\end{tabular}


expressed verbal disapproval only on the first and second occasions of high shock suggestions ( 3 or greater). If the advisor made further suggestions to set high shock levels, the confederate made no verbal comment, but demonstrated behavioral disapproval by setting a 1 or a 2 level shock. Four subjects who did not suggest a level 3 shock or greater on at least one trial were dropped from the experifment.

Veto. Half of the subjects in the cooperation groups and half of the subjects in the noncooperation groups were given the opportunity to "correct" the responder's shock setting. Following the task instructions (Appendix B), subjects in the veto groups were given the following instructions:

Because of the novelty of the experimental situation, it is possible for subjects to make errors on several trials. Errors such as failing to set a shock button, or setting the wrong shock button, sometimes occur. In order to correct for mistakes occurring during the experiment, advisors will be responsible for operating an error-correction system. Directly in front of both advisors is a small box, labeled "error panel". This device is wired into the equipment and controls whether or not a particular trial will continue. As you can see, there are two buttons on the error panel. One is labeled "restart" and the other is labeled "proceed". When the set light flashes, advisors are to suggest to the responders which shock level to set. The responder is then to push one of the shock buttons. At this point, if no errors have been made, advisors are to pusi their proceed buttons, in which case the trial will continue. If, however, an error has been made, the advisor is to push the restart button in order to discontinue that particular trial. In the case that a trial is discontinued, the advisors are to wait for the set light to come on again, and then readvise their responders. only one retrial is allowed for each trial; so that both advisors are to press the proceed button on a correction trial even if an error has been made. 
Folliwng the task instructions, subjects in the noveto condition were given the following instructions:

Directly in front of both advisors is a small box, labeled "error panel". This device is wired into the equipment and controls whether or not a particular trial will continue. As you can see, there are two buttons on the error panel. One is labeled "restart" and the other is labeled "proceed". The restart button is of no concern to us in this study. It is part of a procedure for another experiment which is being conducted in this laboratory. Because of the way in which the equipment is set up, however, both advisors will need to operate the proceed button on each trial. When the set light flashes, advisors are to suggest to the responders which shock level to set. The responder is then to push one of the shock buttons. At this point, advisors are to push their proceed buttons so that the trial will continue.

The two between subject variables defined the experimental conditions under study. Subjects were randomly assigned to one of the following four groups: noncooperation-no veto, noncooperation-veto, cooperation-no veto and cooperation-veto.

Increasing Provocation (trial blocks). This within subject variable was defined as the feedback subjects received concerning the level of shock set by the opponent. During each trial block (composed of six trials) the opponent's mean shock setting increased by one shock level for Part 1 of the experiment. Part 1 was composed of four trial blocks. During trial block one, the opponent set three level 1 shocks and three level 2 shocks (in random order), yielding a mean shock level of 1.5 for trial block one. The mean shock settings for trial blocks two, three, and four were $2.5,3.5$, and 4.5 , respectively. 
Part 2 of the experiment was composed of two trial blocks. The level of provocation remained at 4.5 for both trial blocks.

The number 5 shock was supposedly equivalent to the level of shock judged most unpleasant by the responder during the shock threshold procedure. Subjects were told that the other shocks were percentages of this.

Win-Lose. Within trial block responders won three trials and jost three. The particular order of winning and losing was randomly determined. 


\section{CHAPTER 3}

\section{RESULTS}

The major dependent variables under study were the shock intensities suggested by the advisor during Part 1 and the shock intensities set by the advisor during Part 2 . Two other dependent variables of interest were the subjects' responses on the post-experimental questionnaire and the verbal comments made by subjects during the experiment.

\section{Shock Intensity Suggested (Part 1)}

An analysis of variance was computed for trial one responses to determine if significant differences existed between groups on initial shock intensities suggested. The results of this analysis (Table 1 , Appendix D) indicated no significant differences between groups as a function of the experimental manipulations.

The mean shock intensities suggested following win and following lose trials within each trial block were computed for each subject and a repeated measures analysis of variance was performed on these scores as a function of veto and cooperation. The results of Part 1 are illustrated in Figure 1. Mean shock intensities suggested for each trial block, averaged across the win-lose variable, were plotted for each of the four experimental groups. Mean shock intensities 


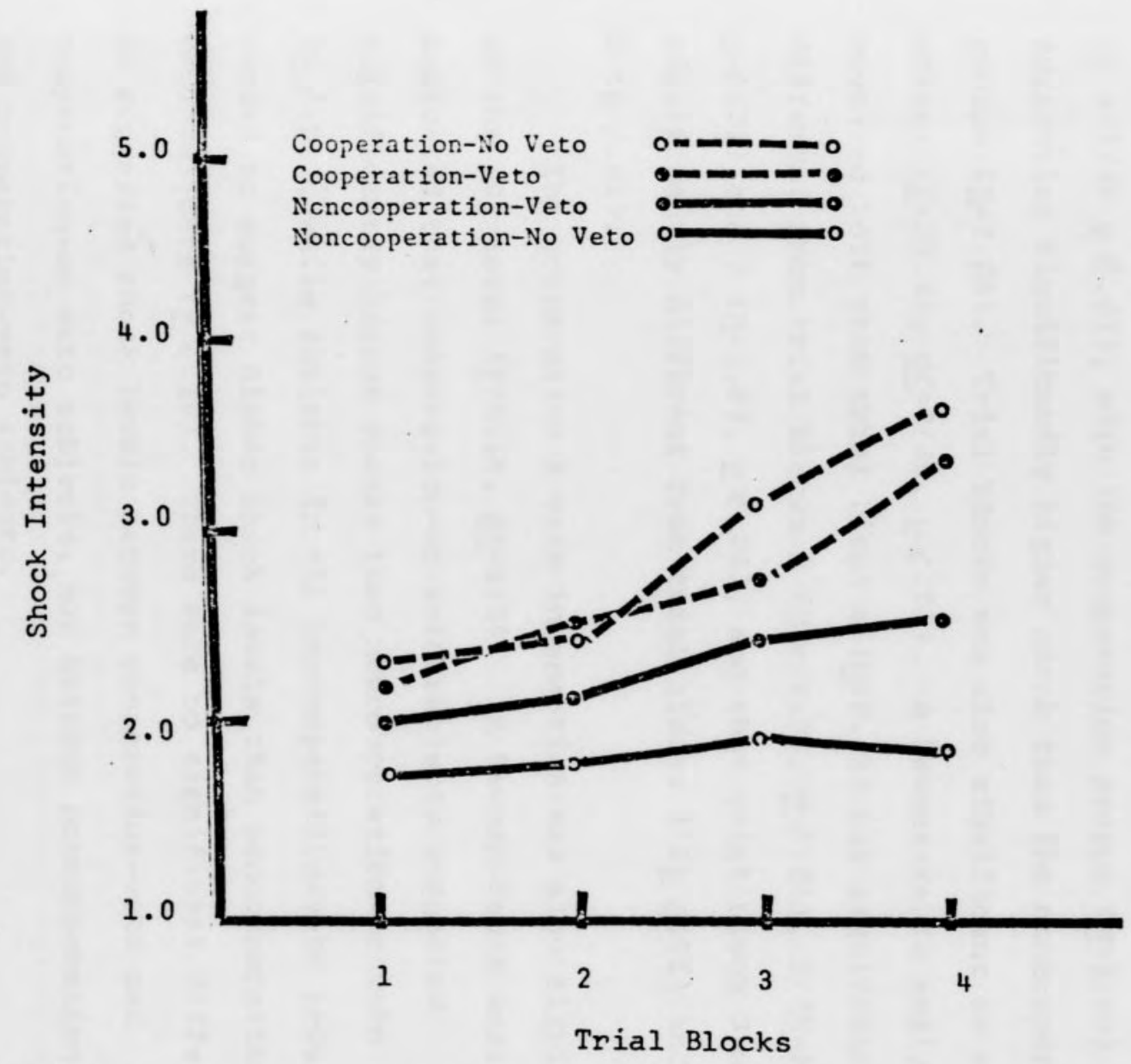

Figure 1. Mean Shock Intensities Suggested During Part 1 as a Function of Cooperation, Veto and Trial Blocks 
recorded as a function of the experimental manipulations are given in Table 2, Appendix D.

The results of the analysis (Table 3 , Appendix D) indicated a significant main effect for cooperation $(\underline{F}=28.21$, $\underline{\mathrm{df}}=1 / 36 \mathrm{p}(.01)$, with the cooperation groups $(\underline{M}=2.80)$ suggesting significantly higher shock than the noncooperation groups $(\underline{M}=2.08)$. Trial blocks was also significant as a thain effect $(\underline{F}=29.38, \underline{d f}=3 / 36, \underline{D}<.01)$. A Newman-Keuls analys is revealed both that trial block $4(11=2.88)$ was significantly different from trial blocks $1(\underline{M}=2.06, \underline{D}<.01), 2(\underline{M}=2.22$, $\mathrm{p}<.01)$ and $3(\underline{M}=2.59, \mathrm{Q}<.05)$, and that trial block 3 was significantly different from trial blocks 1 ( $\mathrm{L}<.01)$ and $2(\mathrm{p}<.01)$.

The cooperation $\mathrm{X}$ veto interaction was also significant at the .05 level $(\underline{F}=4.54, \underline{\mathrm{d}}=1 / 36)$. A Newman-Keuls analysis indicated that cooperation-no veto subjects suggested significantly higher shocks than noncooperation-no veto subjects $(\mathrm{p}<.01)$, while subjects in the noncooperation-veto group tended to suggest higher shock levels than noncooperation-no veto subjects $(\mathrm{p}<.10)$. There were no significant differences in suggested shock levels between cooperation-veto and cooperation-no veto subjects, nor between noncooperation-veto and cooperation-veto subjects.

The cooperation $\mathrm{X}$ trial blocks interaction was also significant $(\underline{F}=10.38, \underline{\mathrm{df}}=3 / 108, \mathrm{p}<.01)$. Newman-Keuls tests indicated that subjects in the cooperation conditions suggested 
significantly higher shocks in trial block $4(M=3.54)$ than in trial block $1(\underline{M}=2.21, \underline{P}<.01)$, trial block $2(\underline{M}=2.48$, $\mathrm{p}<.01)$, or trial block $3(\underline{M}=2.97, \mathrm{p}<.01)$. The analysis was also indicated significantly higher shock suggestions in trial block 3 than trial block 1 ( $\mathrm{L}<.01)$ or trial block 2 $(\mathrm{P}<.01)$. The analysis further revealed no significant differences between trial blocks for noncooperation subjects. The respective means for the four blocks being $1.92,1.96$, 2.21 and 2.23 . Finally, the analysis revealed that subjects in the cooperation conditions suggested significantly higher shock levels than subjects in the noncooperation conditions on all trial blocks (all differences significant at the .01 level).

Magnitude of effect was computed for each significant source of variance. Results indicated that cooperation accounted for $13 \%$, trial. blocks for $10 \%$, the cooperation $\mathrm{X}$ veto interaction for $2 \%$, and the cooperation $\mathrm{X}$ trial blocks interaction for $3 \%$ of the total variance.

\section{Change from Part 1 to Part 2}

An analysis of variance was computed on the data from trial block 4 of Part 1 and trial block 1 of Part 2 to determine if the change in procedure had a significant effect on shock intensity directed toward the opponent. Mean shock levels are given in Table 4, Appendix $D$. The results of the analysis (Table 5, Appendix $D$ ) indicated a significant main effect for trial blocks $(\underline{F}=9.53, \underline{d f}=1 / 36, \underline{p}<.01)$. The change in 
procedure resulted in an overall elevation of shock settings with subjects setting significantly higher shocks on trial block 1 of Part $2(M=3.21)$ than those suggested during trial block 4 of Part $1 \quad(M=2.88)$.

A main effect for cooperation was also significant $(\underline{F}=31.16, \underline{\text { df }}=1 / 36, \mathrm{P}<.01)$ with cooperative subjects setting significantly higher shocks $(M=3.68)$ than noncooperative subjects $(\underline{M}=2.42)$. In addition, the cooperation $x$ veto interaction was significant $(\underline{F}=4.91$, $\underline{f}=1 / 36, \underline{p}<.05)$. A NewmanKeuls analysis indicated that cooperation-no veto subjects set significantly higher mean shock levels $(\underline{M}=3.77)$ than did noncooperation-no veto subjects $(M=2.00, \underline{P}<.01)$. The difference in mean shock level for noncooperation-veto subjects $(\underline{M}=2.83)$ and noncooperation-no veto subjects reached significance at the .10 level. The remaining comparisons were not statistically significant.

Magnitude of effect was computed for cooperation, trial blocks and the cooperation $\mathrm{X}$ veto interaction. These variables accounted for $23 \%, 1 \%$ and $3 \%$ of the total variance, respectively.

\section{Shock Intensity Set (Part 2)}

Trial one responses for Part 2 were analyzed with a two way analysis of variance. The results of this analysis, shown in Table 6 , Appendix $D$, indicated a significant effect for cooperation $(F=7.53, \underline{d f}=1 / 36, \underline{p}<.01)$ with cooperative 
subjects setting significantly higher shock levels $(\underline{M}=2.80)$ than noncooperative subjects $(M=2.00)$. The cooperation $X$ veto interaction also reached significance at $\mathrm{D}<.10 \quad(\underline{F}=2.94$, $\underline{d f}=1 / 36)$. A Newman-Keuls analysis indicated that the significance was due to the difference in scores between cooperation-no veto and noncooperation-no veto subjects. Subjects in the cooperation-no veto group set significantiy higher shocks on trial one $(\underline{M}=3.00)$ than did noncooperationno veto subjects $(\underline{M}=1.70, \underline{p}=\langle .01)$. No other significant trial one differences were observed.

A repeated measures analysis of variance was computed for mean shock settings following win and lose trials during Part 2; these means are given in Table 7, Appendix D. The results of the analysis are shown in Table 8 , Appendix D. The main effect for cooperation was significant at $\mathrm{D}<.01$ $(\underline{F}=16.91, \underline{d f}=1 / 36)$, with cooperative subjects setting significantly higher shocks $(M=3.81)$ than noncooperative subjects $(M=2.75)$. The cooperation $X$ veto interaction was also significant $(\underline{F}=6.54, \underline{\mathrm{df}}=1 / 36, \mathrm{D}<.025)$. A Newman-Keuls analysis indicated that subjects in the cooperation-no veto group set significantly higher shocks than noncooperationno veto subjects $(M=2.24, \mathrm{Q}<.01)$. The difference in mean shock settings between noncooperation-veto subjects and noncooperation-no veto subjects was significant at $\mathrm{D}<.0506$. The mean shock settings for cooperation-veto subjects ( $M=3.66$ ) did not differ significantly from that of the cooperationno veto subjects $(M=3.96)$. In addition, cooperation-veto 
subjects did not set significantly higher shocks than did the noncooperation-veto subjects $(M=3.26)$.

Magnitude of effect computed for cooperation and the cooperation $X$ veto interaction indicated that these variables accounted for $16 \%$ and $6 \%$ of the total variance, respectively.

\section{Questionnaire Responses}

Questionnaire responses were analyzed using a multivariate analysis of variance. Separate multivariate analyses were computed for the subjects' ratings of the responder and for the subjects' ratings of themselves on 31 attributes.

The results of the multivariate analysis for ratings of the responder (summarized in Table 9, Appendix D) indicated a significant main effect for cooperation (approximate $\underline{F}=4.65, \underline{d f}=6 / 31, \underline{D}(.01)$ and a cooperation $X$ veto interaction significant at $\mathrm{P}<.10$ (approximate $\underline{F}=2.10$, df $=6 / 31$ ). Subsequent univariate analyses indicated that subjects rated cooperative responders as stronger $(\mathrm{D}<.05)$, braver $(\mathrm{P}<.05$, more reasonable $(\mathrm{D}<.05)$, more assaultive $(\mathrm{P}<.05)$, more unsympathetic $(\mathrm{p}<.05)$, more cooperative $(\mathrm{P}<.01)$, more competitive $(\mathrm{p}<.01)$, more aggressive $(\mathrm{p}<.05)$, more revengeful $(\mathrm{D}<.01)$, and more active $(\mathrm{Q}<.05)$ than they did noncooperative responders. Univariate analyses also revealed a tendency for cooperative subjects to rate their responders as less predictible $(\mathrm{P}<.06)$, less maladjusted $(\mathrm{p}<.07)$, less ill-humored $(\mathrm{p}<.13)$, smaller $(\mathrm{P}<.14)$, and more bloodthirsty $(\mathrm{P}<.20)$. 
An analysis of ratings on the variable of cowardice indicated a significant cooperation $\mathrm{X}$ veto interaction $(\mathrm{p}<.05)$. Newman-Keuls post-hoc tests revealed that noncooperation-veto subjects rated their responders as being more cowardly as compared to ratings given by noncooperationno veto subjects $(\mathrm{P}<.05)$ and cooperation-no veto subjects rated their responders significantly higher in cowardice than did cooperation-veto subjects $(\mathrm{p}<.01)$. Univariate analyses indicated that the cooperation $X$ veto interaction also approached significance for the variables of strength $(\mathrm{D}<.13)$, friendliness $(\mathrm{p}<.16)$, leadership $(\mathrm{p}<.17)$, deceitfulness $(\mathrm{p}<.13)$, rejection $(\mathrm{p}<.14)$ and passivity $(\mathrm{p}<.06)$. Cooperationveto subjects showed a tendency to rate their responders as more active and more of a leader; noncooperation-veto subjects rated their responders as more unfriendly and more deceitful; and noncooperation-no veto subjects rated their responders as more rejecting when compared to ratings given by subjects in the other three groups. In addition, cooperation-no veto subjects rated their responders highest on the variable of strength.

Although the multivariate analysis revealed that overall the variable of veto did not significantly affect the subjects' ratings of the responder, the univariate analyses indicated significant effects of veto for two particular items. Veto subjects rated their responders as weaker $(\underline{p}<.05)$ and more dependent $(\mathrm{p}<.05)$ than did no-veto subjects. There was also 
a tendency for veto subjects to rate their responders as less destructive $(\underline{p}<.17)$, more cowardly $(\underline{L}<.14)$, more unreasonable $(\mathrm{P}<.19)$, more relaxed $(\mathrm{P}<.09)$, more submissive $(\mathrm{p}<.16)$, less bloodthirsty $(\mathrm{p}<.10)$ and less revengeful $(\mathrm{P}<.16)$ than no veto subjects. The lack of multivariate significance for veto, however, renders the effects of this variable, noted above, merely suggestive.

The multivariate analysis for ratings of self (see Table 10, Appendix D) indicated a significant main effect for veto (approximate $\underline{F}=3.01$, $\underline{\mathrm{df}}=6 / 31, \mathrm{p}<.05$ ). Univariate analyses indicated that veto subjects rated themselves as significantly larger $(\mathrm{Q}<.05)$ than did no-veto subjects. Univariate analyses also revealed a tendency for veto subjects to rate themselves as less competitive $(\underline{p}<.13)$ and less bloodthirsty $(\mathrm{p}<.09)$ than no-veto subjects.

The cooperation $X$ veto interaction, although not significant in the multivariate analysis, was significant at the .05 level in the univariate analyses for the variables of strength, tenseness, and attractiveness. Newman-Keuls analyses indicated that noncooperation-veto subjects rated themselves as significantly stronger than noncooperation-no veto subjects $(\mathrm{P}<.05)$ and cooperation-veto subjects $(\mathrm{P}<.05)$. In addition, noncooperation-veto subjects rated themselves as significantly more relaxed than did noncooperation-no veto subjects $(\mathrm{P}<.05)$ or cooperation-veto subjects $(\mathrm{P}<.05)$. On the variable of attractiveness cooperation-veto subjects rated 
themselves as less attractive than did either cooperationno veto subjects $(\mathrm{P}<.05)$ or noncooperation-veto subjects $(\mathrm{p}<.05)$.

The cooperation $\mathrm{x}$ veto interaction in the univariate analyses also approached significance for the variables of destructiveness ( $\mathrm{p}<.10$, cowardice $(\mathrm{p}<.19$ ), intelligence $(\mathrm{p}<.07)$, badness $(\underline{\mathrm{p}}<.17)$, largeness $(\mathrm{p}<.08)$, ill-humor $(\mathrm{p}<.17)$ and sociability $(\mathrm{p}<.14)$. Cooperation-veto subjects rated themselves as more cowardly, less intelligent and more unsociable; noncooperation-veto subjects rated themselves as larger; cooperation-no veto subjects rated themselves as more destructive; and noncooperation-no veto subjects rated themselves as more ill-humored and less good when compared to ratings given by subjects in the other three groups.

Although multivariate significance was not obtained for the variable of cooperation univariate analyses indicated a greater tendency for cooperative subjects to rate themselves as bad $(\mathrm{p}<.17)$, less ill-humored $(\mathrm{p}<.08)$, and less rejecting $(\mathrm{p}<.20)$ when compared to ratings given by noncooperative subjects. Once again, in light of multivariate non-significance for cooperation, these results can only be considered suggestive.

A univariate analysis of responses to the question "How well do you think you and your responder got along?" revealed a significant main effect for cooperation $(\underline{F}=4.21$, $\mathrm{df}=1 / 36, \mathrm{p}(.05)$. Subjects who were paired with noncooperative responders indicated that they got along with the responder 
less well than did subjects paired with cooperative responders.

A univariate analysis of responses to the question

"Rate the painfulness of the shocks you received" revealed that the cooperation $\mathrm{X}$ veto interaction approached significance $(\underline{F}=3.23, \underline{d f}=1 / 36, \underline{p}<.09)$ with noncooperation-veto and cooperation-no veto subjects demonstrating a tendency to rate the shocks as less painful than subjects in the other two groups.

The results of a univariate analysis of responses to the question "Would you like to be with her (the responder) in this experiment again?" revealed a tendency for noncooperative subjects to prefer not to be with the responder again when compared to responses given by cooperative subjects $(\underline{F}=2.31, \underline{d f}=1 / 36, \mathrm{p}<.14)$. The cooperation $\mathrm{X}$ veto interaction was significant at $\underline{p}<.05(\underline{F}=4.11$, $\underline{\mathrm{d}}=1 / 36)$. Newman-Keuls tests revealed that the significance was due to differences between the noncooperation-veto and cooperation-veto subjects. Noncooperation-veto subjects expressed a greater desire not to be with the responder again $(\underline{P}<.05)$.

Univariate analyses were also computed for responses to the questions, "How effective an advisor do you think you were?" "Did the shocks seem to bother the responder?" "Did it bother you to watch the responder receive a shock?" and "Did you enjoy this experiment?". None of these analyses revealed significant effects for responses to these questions. 


\section{Verbal Comments}

Verbal comments made by subjects during the experiment were recorded and subsequently rated by two persons as falling into one of the following six categories: "aggressive instigation", i.e. the desire to hurt or give the opponent a high shock, "pacifistic instigation", i.e. to be kind to the opponent or give her a low shock, "concern for the " responder", i.e. empathy or concern for the shock received and/or a desire to keep the responder from being hurt, "suspicion", i.e. doubt about any aspect of the experiment, "win", i.e. concern or desire to win independent of the other categories and "other", i.e. a catchall for comments not fitting into one of the above five categories. A total of 738 comments were rated independently by each rater. Interjudge reliability was calculated at $83 \%$. Only comments in which both raters agreed upon were included in the statistical analyses for the appropriate categories. All comments which were rated differently by the two raters were placed in a separate category entitled "misses". In addition, all comments which were non-task related or incomprehensible were placed into a "comments" category.

An analysis of variance was computed for the number of comments made to determine if significant differences existed as a function of veto and cooperation. The results of this analysis (Table 11, Appendix D) revealed no significant 
differences between groups.

Verbal comments were analyzed separately for Part 1 and Part 2 of the experiment. In each case, for every subject a percentage of the total number of comments was computed for comments in each of the eight categories. Separate analyses of variance were computed on these percentages as a function of veto and cooperation. The results of analyses computed for the categories of "aggressive instigation", "pacifistic instigation", "concern for the responder", "other", "win" and "misses" indicated no significant effects for Part 1 or Part 2 comments.

An analysis computed for the category of "comments" for Part 1 (Table 12, Appendix D) indicated a significant main effect for cooperation $(\underline{F}=10.06$, df $=1 / 36, \underline{p}<.01)$ with cooperative subjects making a significantly higher percentage of statements in the "comments" category than did noncooperative subjects. In addition, the main effect of veto reached significance at $\mathrm{R}<.08 \quad(\underline{F}=3.40, \underline{\mathrm{df}}=1 / 36)$ with veto subjects making a higher percentage of statements in the "comments" category than did no-veto subjects.

An analysis of Part 2 "comments" (Table 13, Appendix D) indicated a significant main effect for cooperation $(F=7.60$, $\mathrm{df}=1 / 36, \mathrm{p}(.01)$ with cooperative subjects making a higher percentage of statements in the "comments" category than noncooperative subjects. 
Magnitude of effect was computed for analyses of the "comments" categories and indicated that cooperation accounted for $13 \%$ of the total variance for the Part 1 analysis and $15 \%$ of the total variance for the Part 2 analysis. Veto accounted for $2 \%$ of the total variance in the Part 1 analysis.

Analyses computed for comments of "suspicion" indicated no significant effects for Part 1, but yielded a significant main effect of cooperation for Part 2 ( $\underline{F}=4.36$, df $=1 / 36, \mathrm{p}<.05$, see Table 14, Appendix D). Noncooperative subjects made a significantly higher percentage $(\underline{M}=2 \%)$ of "suspicion" comments than did cooperative subjects ( $M=0 \%$ ) during Part 2. Magnitude of effect was computed and indicated that cooperation accounted for $10 \%$ of the total variance for the Part 2 analysis of "suspicion" comments. Subjects who were suspicious doubted the presence of opponents in the adjoining room. Confederates were trained to respond to suspicious comments by noting that they had seen the experimenter bring two subjects into the second room or that their roommate was in the same experiment and actually met her opponents. There was no evidence whatsoever to suggest that any subject doubted the truthfulness or the genuineness of the confederate. 


\section{CHAPTER 4}

\section{DISCUSSION}

The results of the present investigation reaffirmed the cooperation-noncooperation phenomenon. Subjects who , were paired with cooperative responders suggested significantly higher shock levels than did subjects paired with noncooperative responders. The effect was established during Part 1 and maintained throughout Part 2. The hypothesis that advised shock settings would be significantly higher for subjects paired with cooperative responders than for subjects paired with noncooperative responders was therefore confirmed.

During Part 1, as in earlier research (Gaebelein, 1973a, 1973b; Gaebelein \& Hay, 1974, 1975), the hypothesis was confirmed that increasing provocation from the victim would effect an increase in the amount of instigated aggression. However, as predicted, the increase in suggested shock level was partially dependent upon the variable of cooperation, as indicated by the significant cooperation $\mathrm{X}$ trial blocks interaction. Subjects in the cooperation groups suggested significantly higher shocks than noncooperative subjects on each trial block. Furthermore, cooperative subjects demonstrated significant increases across trial blocks whereas no significant increases were found for noncooperative subjects. 
Contrary to the prediction that the level of advised shock would be significantly higher following lose trials, as compared to the advised shock following win trials, the main effect for win was not significant. The results of Gaebelein's (1973a, 1973b) research indicated a significant increase in advised shock levels following trials which the responder lost as compared to those which the responder won. However, this finding was not replicated in Gaebelein and Hay's (1974, 1975) experiments. Gaebelein and Hay (1974) commented that subjects apparently responded to the opponent's intended level of attack as indicated by the feedback jights regardless of whether the intended shock was actually delivered. Because the Gaebelein and Hay (1974, 1975) studies were somewhat more involved than the Gaebelein (1973a, 1973b) studies, with respect to the variables to which the subject needed to attend it seems plausible that the relative importance of the win-lose variable may have been perceived by the subject to be less in the former than in the latter investigations. Similarly, the nonsignificance of the win-lose variable in the present investigation may have been due to the subject's perception of that variable as one of relatively little importance and therefore, one to which she was less likely to attend.

As predicted, the main effect of veto was found to be nonsignificant. The significant cooperation $\mathrm{X}$ veto interaction 
for Part 1 and Part 2 indicated that the veto manipulation affected shock suggestions differentially depending upon the particular level of cooperation. Veto power had no significant effect upon suggested shock level for cooperative subjects but tended to elevate shock suggestions for subjects paired with noncooperative responders, a result which is commensurate with the power interpretation of the noncooperation phenomenon. That is, subjects probably felt greater control over the situation and hence did not have to suggest only lower shock intensities to maintain a sense of power. This suggestion is confirmed by the self-rating data. Subjects with veto power rated themselves as larger, and the subjects in the noncooperation-veto group, in particular, saw themselves as stronger and more relaxed, as well as viewing the responder as more cowardly.

It should be noted that only one subject in the noncooperation-veto group actually pushed the restart button during Part 1. Even though only one subject in the noncooperation-veto group actually tested her power and had it affirmed, the level of shock for Part 1 in that group was significantly higher (at $\mathrm{P}<.10$ ) than that in the noncooperation-no veto group. The fact that the restart button was used by only one subject raises some question as to whether power alone was operating within the noncooperation-veto group. It seems probable that compliance was also operating, i.e. subjects realized their power but chose not to use it. The possibility 
of conformity seems unlikely because the subjects' ratings of their partners indicated that the responders were seen as unfriendly and deceitful. The notion that compliance was operating in combination with power is supported by the finding that the noncooperation-veto group tended to show a greater increase from Part 1 to Part 2 than any other group of subjects. That is, when the pressure to comply in the direction of nonaggression was removed, these subjects increased in aggressiveness. Furthermore, the power hypothesis predicted that with the acquisition of power, noncooperationno veto subjects would increase the level of shock directed toward the opponent and thus the difference between this group and the noncooperation-veto group would be reduced. During Part 2, however, with subjects setting the shock buttons themselves this difference became more pronounced, a finding which contradicts the predictions of the power hypothesis. Noncooperation-no veto subjects showed only a slight increase in shock set from trial block 1 of Part 2 to trial block 2 of Part 2 whereas noncooperation-veto subjects showed a somewhat greater increase. It is possible that since noncooperation-no veto subjects were not given the expectation of control over the responder (as were noncooperation-veto subjects) their high level instigations extinquished. Perhaps additional trials may have been required to reestablish high shock settings during Part 2 . 
Finally, the change in procedure from Part 1 to Part 2 resulted in an overall elevation of the intensity of shock directed toward the opponent. This was probably because of prolonged exposure to high level attack from the opponent. Similar results have been reported by other investigators (Epstein \& Taylor, 1967; Gaebelein \& Mander, 1975; Pisano \& Taylor, 1971). However, another possible explanation may' lie in the change in the task the subject was to perform. In Part 2, there was no mediator between the subject and her victim, whereas there was in Part 1 . It may be that the absense of the mediator in some way facilitated the elevation of shock levels. This hypothesis seems untenable, in that Tilker (1970) has suggested that when subjects are made to feel responsible for a punitive act they are more likely to interfere with aggressive attacks against a victim; and Kilham and Mann (1974) have shown that direct executants (i.e., as in Part 2 in the present study) should be less aggressive than a transmitter (i.e., advisor in the present study). During Part 2, subjects clearly had total responsibility for deciding which shock intensity to deliver and for actually delivering the level of their choice. Therefore, if the change in procedure from Part 1 to Part 2 was in part responsible for a change in the subjects' shock setting behavior a decrease in the intensity of shock directed toward the opponent should have resulted. Since, in fact, an 
elevation in shock level was observed for Part 2, it seems unlikely that the mere change in procedure was responsible for a significant change in the subjects' behavior.

To summarize, the results of Part 1 tend to support the power hypothesis in that subjects in the noncooperationveto group demonstrated an elevation in suggested shock when compared to noncooperation-no veto subjects. The difference between these two noncooperation groups was, however, of marginal significance at $\mathrm{p}<.10$. However, since this difference became more pronounced by Part 2 of the study (i.e., the $\mathrm{D}$ value decreased to .056 and the amount of variance accounted for in the cooperation $\mathrm{X}$ veto interaction increased from $2 \%$ to $6 \%$ ) the power hypothesis can be questioned. Evidence indicated that compliance was operative while there was no support for conformity. Because of the apparent operation of several factors at once, the data from each subject was evaluated. Each subject's mean advised shock level (for Part 1) and mean shock level set (for Part 2) was computed and plotted. The results for the noncooperationveto group are shown in Figure 2. For the purpose of comparison, similar graphs are given for the cooperation-veto, cooperation-no veto, and noncooperation-no veto groups in Figures 3, 4, and 5 respectively. Three clearly distinquishable patterns are visable in Figure 2. Three subjects suggested low shocks throughout Part 1 and continued to set low shocks 


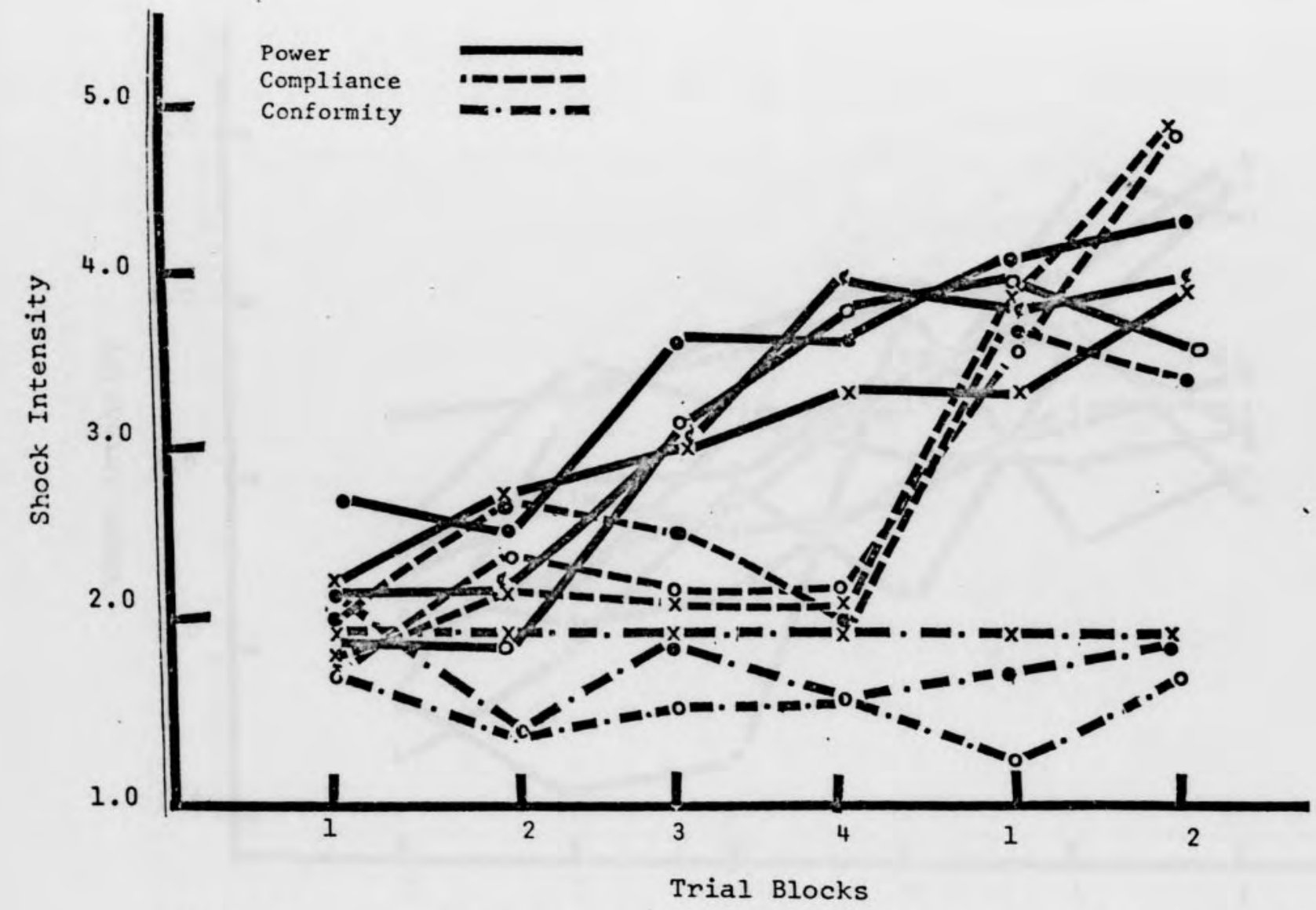

Figure 2. Shock Intensities for Part 1 and Part 2 for Noncooperation-veto Subjects as a Function of Trial Blocks 


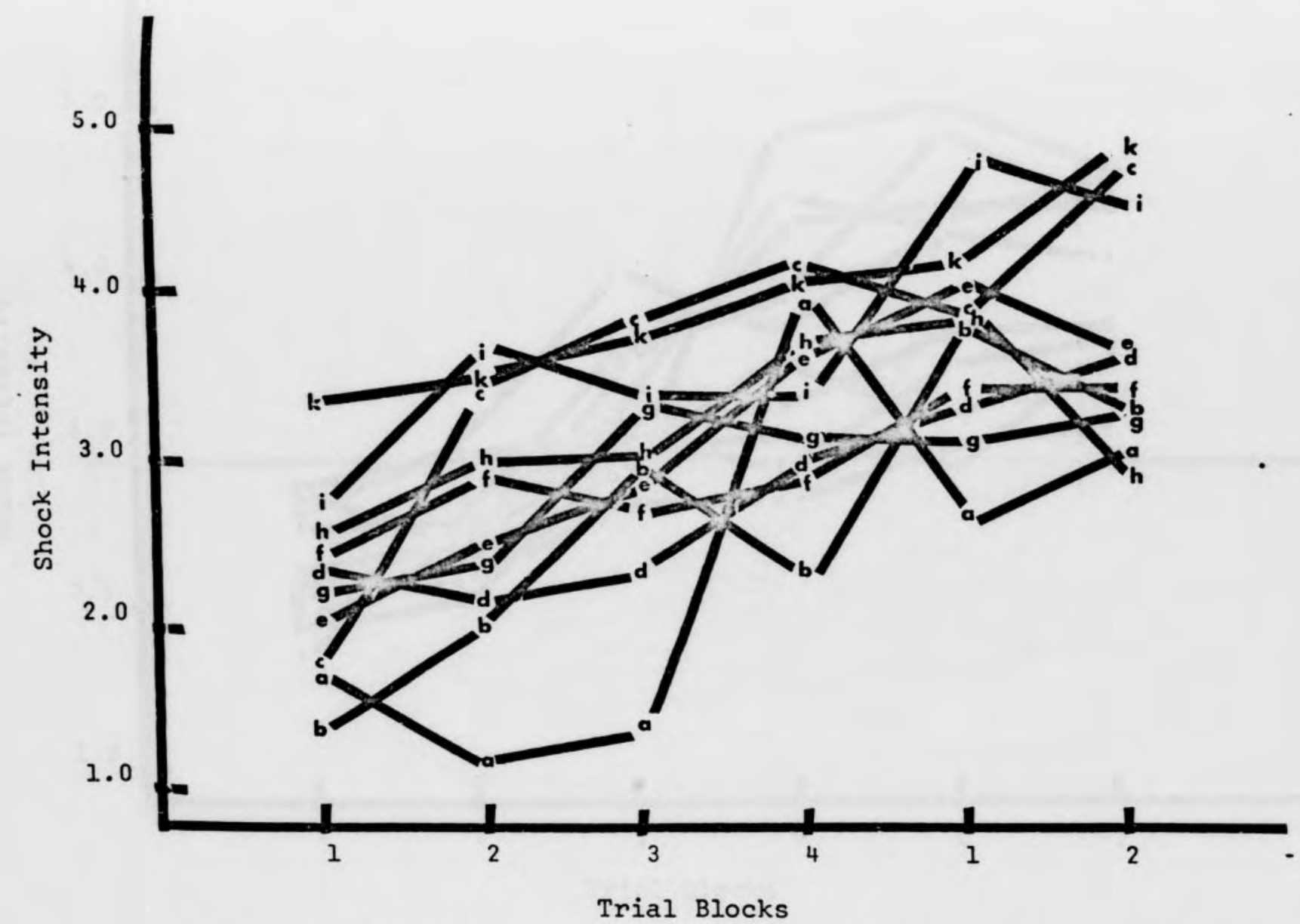

Figure 3. Shock Intensities for Part 1 and Part 2 for Cooperation-veto Subjects as a Function of Trial Blocks 


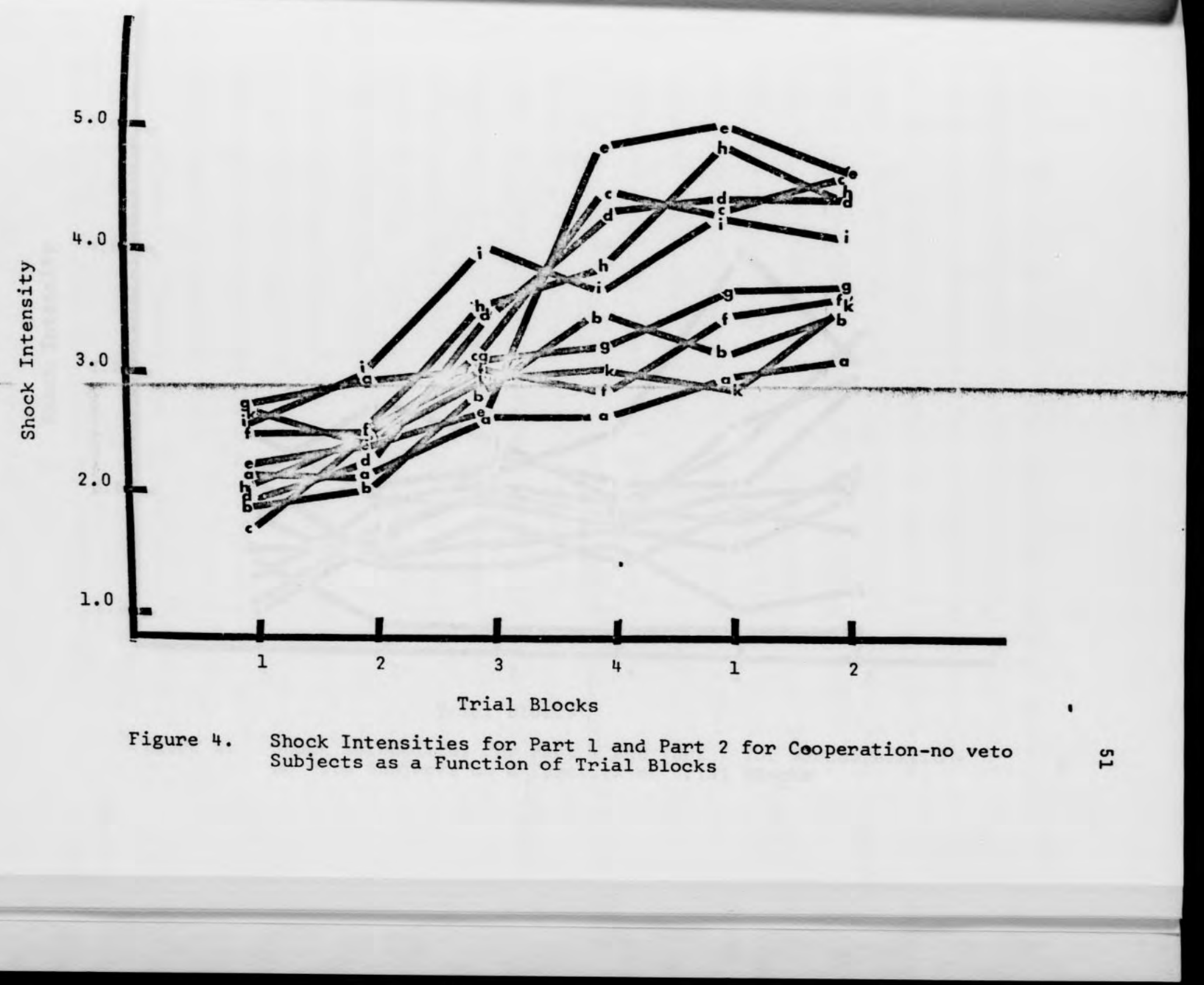




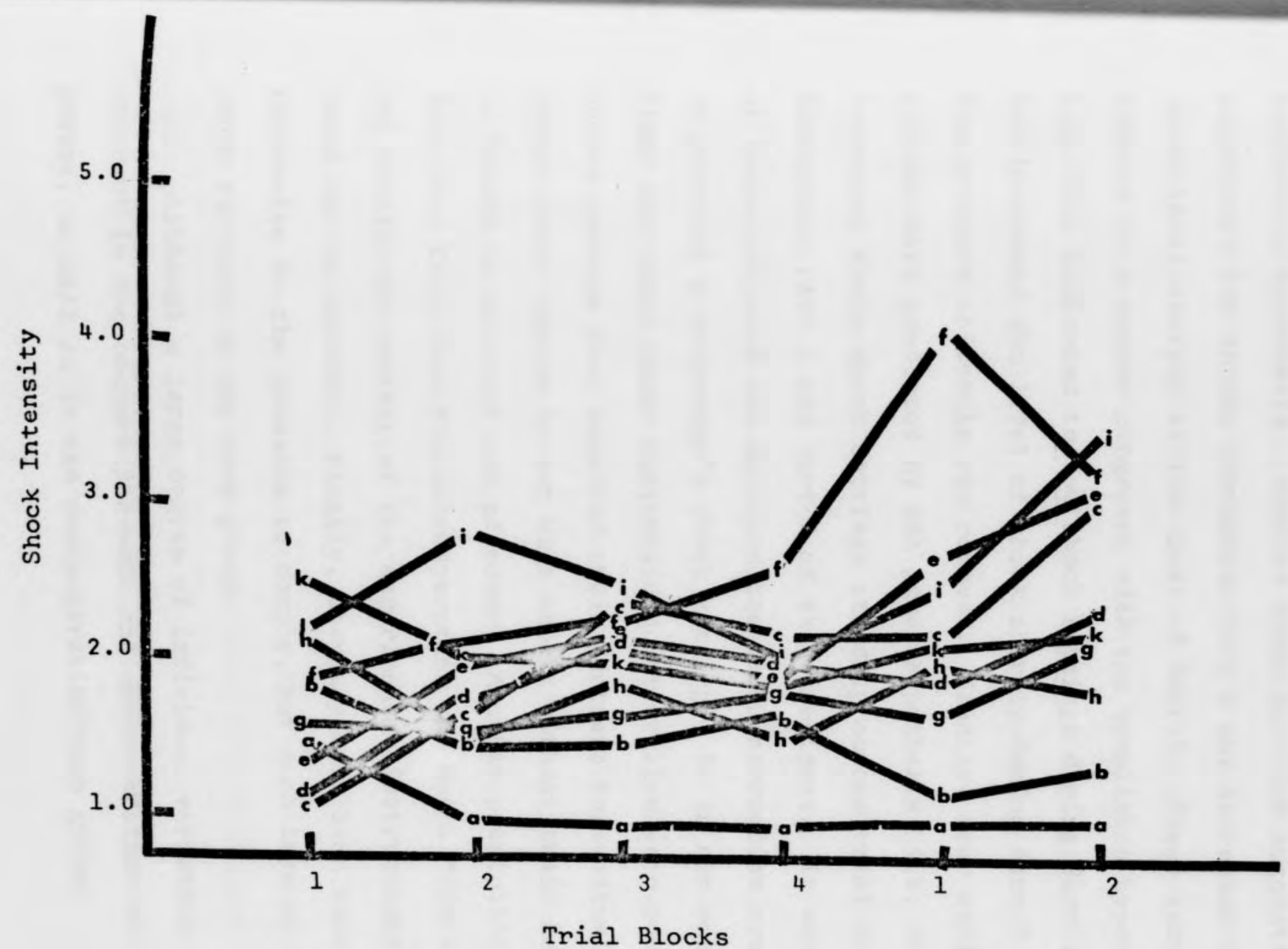

Figure 5. Shock Intensities for Part 1 and Part 2 for Noncooperationno veto Subjects as a Function of Trial Blocks 
during Part 2. These subjects behaved as predicted by the conformity hypothesis. Another three subjects suggested relatively low shocks throughout Part 1 but increased the shock level sharply at the onset of Part 2. These subjects behaved in a manner congruent with the compliance hypothesis, i.e. they conformed to low shock settings during Part 1 but increased the level of shock sharply during Part 2 when the pressure to comply was removed. Finally, four subjects yielded data predicted by the power hypothesis, i.e. they increased their shock settings steadily across trial blocks throughout Part 1 and Part 2 of the experiment. It was one of these subjects who employed the error correction system to overrule a responder's shock setting. It is not entirely clear why three power subjects did not utilize veto power, unless perhaps they expected their partners to eventually accept their advice to set high shocks without their having to resort to an overt use of power. Another possibility is that they felt that the noncooperation was not a "mistake" and within the context of the experimental instructions, chose not to correct. Finally, they may have been somewhat responsive to the pressure to comply, but much less so than other subjects in the same group.

Although a large degree of individual variation is apparent in the cooperation-veto and noncooperation-no veto groups, as well as in the noncooperation-veto group, 
examination of Figures 3,4 , and 5 suggests that the variation in these groups is of random arrangement. Furthermore, the magnitude of individual differences was assessed via separate repeated measures analyses of variance for each group as a function of subjects, blocks, and win. Only the data from Part 1 were analyzed. The results of these analyses can be found in Tables 15, 16, 17 and 18, Appendix D. of particular interest, was the finding that although the subjects effect was highly significant in all analyses the subjects effect accounted for only $22 \%$ of the total variance in the cooperationveto group, $6 \%$ in the cooperation-no veto group, $32 \%$ in the noncooperation-no veto group, and $42 \%$ in the noncooperationveto group.

It is apparent from Figure 2 that the data points plotted in Figure 1 for the noncooperation-veto group are a compromise between three clearly distinct patterns, none of which are accurately represented by the group plot in Figure 1. This fact, plus the differences in the amount of variance accounted for with respect to the subjects effects, provides compelling evidence that the hypotheses of power, conformity and compliance are all viable and that at least in the present. study all were operating with different individuals. Further research is necessary to identify individual characteristics related to the response patterns identified in the present study. 
Because of the large individual differences which were found to exist in the noncooperation-veto group, the questionnaire responses were re-examined for the subjects in this group. The ratings of self and of responder for each attribute were averaged for the conformity, compliance and power subjects separately. Though sample sizes are too small for statistical comparison, examination of the different patterns of response give further post hoc support for the thesis that all three patterns, i.e. power, compliance and conformity, were operative within the noncooperation-veto group. The means are presented in Tables 19 and 20, Appendix D. As indicated in Table 19, power subjects tended to rate the responder as being more assaultive, more illhumored, more aggressive and more revengeful than did compliance or conformity subjects, with conformity subjects giving the lowest ratings. With regard to ratings of self, Table 20 illustrates that power and compliance subjects rated themselves about equally across the traits of aggressiveness, revengefulness, cruelty and competitiveness. Both power and compliance subjects rated themselves as being higher on these traits, as well as the traits of destructiveness, assaultiveness and bloodthirstyness when compared to ratings given by conformity subjects.

There was also a tendency for conformity subjects to rate the responder as being stronger, more of a leader, more active, more dominant, less uncooperative and more independent 
when compared to ratings given by power and complaince subjects. On the other hand, conformity subjects rated themselves as being less of a leader, less active, less dominant and less uncooperative when compared to ratings given by power and compliance subjects.

In addition, conformity subjects rated themselves and their responders as being more fair, more reasonable, and more sympathetic than did power or compliance subjects. Conformity subjects rated their responders as being less cowardly but themselves as being more cowardly when compared to ratings given by complaince or power subjects. This may indicate that conformity subjects hesitated to utilize their veto power out of fear of disapproval. Since the ratings of the responder were less negative for conformity subjects, internalization of the norm not to hurt may be indicated. Whether this norm was instilled during the task or whether it was an established pattern triggered by the experimental situation is impossible to say.

Responses to the last six questions of the postexperimental questionnaire were re-examined for power, compliance and conformity subjects in the noncooperation-veto group. Mean ratings for these six items are given in Table 21 , Appendix D. In response to the question, "Did the shocks seem to bother the responder?" power subjects tended to report that they thought the shocks bothered the responder to a 
greater extent than did conformity or compliance subjects. Power subjects may have suggested and set higher shock levels during the experiment because they felt that the opponent was causing greater pain to the responder than did complaince or conformity subjects. On the other hand, they may have rated the shocks as being more painful for the responder as a justification for suggesting and setting higher shocks. Compliance subjects reported that they thought the shocks bothered the responder to a lesser extent when compared to ratings given by power and conformity subjects. Furthermore, in response to the question, "Did it bother you to watch the responder receive a shock?" compliance subjects reported that it bothered them less than it did power or conformity subjects.

In response to the questions "How well do you think you and your responder got along?" and "lould you like to be with her in this experiment again?" conformity subjects reported that they thought they got along better with the responder than did compliance or power subjects and conformity subjects expressed a greater desire to be with the responder again.

Finally, in response to the question, "Did you enjoy this experiment?" compliance subjects indicated that they enjoyed the experiment less than power or confocmity subjects. 
Adams, J.S. Inequity in social exchange. In L. Berkowitz (Ed.), Advances in Experimental Social Psychology, Volume 2, New York: Academic Press, 1965.

Berkowitz, L. Aggression: A Social Psychological Analysis, New York: McGraw-Hill, 1962.

Borden, R:J. \& Taylor, S.P. The social instigation and control of physical aggression. Journal of Applied Social Psychology, $1973, \underline{3}, 354-361$.

Buss, A.H. Physical aggression in relation to different frustrations. Journal of Abnormal and Social Psychology, $1963,67,1-7$.

Epstein, S. \& Taylor, S.P. Instigation to aggression as a function of degree of defeat and perceived aggressive intent of the opponent. Journal of Personality, 1967, $\underline{35}, 265-289$.

Gaebelein, J.W. Third Party Instigation of Aggression: An Experimental A Dproach. Doctoral Dissertation, Kent University, 1971.

Gaebelein, J.W. Third party instigation of aggression: An experimental approach. Journal of Personality and Social Psychology, $1973 a, \underline{27}, 3 \overline{89-395 .}$

Gaebelein, J.W. Instigative aggression in females. Psychological Reports, 1973b, 33, 619-622.

Gaebelein, J.W. Personal Communication. December 1, 1974.

Gaebelein, J.W. \& Hay, W.M. Third party instigation of aggression as a function of attack and vulnerability. Jounnal of Research in Personality, 1974, $7,324-333$.

Gaebelein, J.W. \& Hay, W.M. The effects of verbal and motor noncooperation on third party instigation of aggression. Journal of Research in Personality, 1975, In Press. 
Gaebelein, J.W. \& Mander, A.M. Consequences for the target of aggression as a function of aggressor and instigator roles: Two experiments. Manuscript submitted for publication, 1974 .

Kiesler, C. \& Kiesler, S. Conformity. Reading, Massachusetts: Addison Wesley Publishing Company, 1969.

Kilham, W. \& Mann, L. Level of destructive obediance as a function of transmitter and executant roles in the Milgram Obedience Paradigm. Journal of Personality and Social Psychology, 1974, 29, 696-702.

Milgram, S. Some conditioning of obedience and disobedience to authority. Human Relations, 1965, 18, 57-65.

Pisano, R. \& Taylor, S.P. Reduction of physical aggression: The effects of four strategies. Jounnal of Personality and Social Psychology, 1971, 19, 237-242.

Schopler, J. Social power. In L. Berkowitz (Ed.) Advances in Experimental Social Psychology, Volume 2, New York: Academic Press, 1965.

Taylor, S.P. Aggressive behavior and physiological arousal as a function of provocation and the tendency to inhibit aggression. Journal of Personality, 1967, 35, 297-310.

Taylor, S.P. Communicated aggressive intent, social anxiety and aggressive behavior. Paper presented at symposium on Arousal and Control of Human Aggression, Midwestern Psychological Association, Chicago, 1973.

Tilker, H.A. Socially responsible behavior as a function of observer responsibility and victim feedback. Journal of Personality and Social Psychology, 1970, 14, 95-100.

Tursky, B., Watson, P.H. \& O'Connell, D.N. A concentric shock electrode for pain stimulation. Psychophysiology, 1965, I, 296-299. 
APPENDIX A

Shock Threshold Instructions

"The following instructions are for the Advisor:

'I am going to give you a series of shocks, beginning with an extremely weak one and working up in gradual' steps to a point where you feel that it is quite unpleasant. When the first shock is presented to you, it will be so weak that you probably will not feel it. When you do first feel it, it will be like a tingling, similar to the sensation you have when your arm falls asleep. Next it will be a sort of vibration, and your hand may involuntarily move or close a little bit. This is a normal reaction. The next stage feels like a deep jab under the skin, and is what we call pain. I want you to tell me when the intensity of the shock reaches a point where it feels definitely unpleasant, but not yet painful. I will be able to hear you, and you will be able to hear me through this intercom.' I will now repeat the same procedure for the Responder." 


\section{APPENDIX B}

\section{Task Instructions}

"The following instructions are for the Responder:

'The purpose of this experiment is to determine the effects of competition on the speed with which a finger can be pulled off a reaction time key. Two responders, situated in separate rooms, are participating in this experiment. Both of you have the same apparatus in front of you and the same task to perform.'

'You are to depress the reaction time key and hold it down when you see the press light go on. At some interval after this light goes on, the amber light behind the reaction time key will go on. You are both to remove your fingers from the reaction time key as fast as you can when the amber signal light goes on. of course you will both receive the amber signal at the same time. The object of each trial is to get your finger off as fast as possible in order to beat your competitor. The person who does not get her finger off in the shortest time, that is, the person with the slower reaction time, will receive a shock.'

'There are five different intensitites of shock one can get if one has the slower reaction time. The degree of shock one actually gets depends on the degree of shock the competitor chose to store in the apparatus before the trial began.' 
'Before each trial, when you see the set light go on, you will immediately set the amount of shock you wish your opponent to get if you should be faster on the coming trial. You will do this by pressing one of five buttons. These buttons are situated to your right. The one button corresponds to the least intense shock, the five button to the most intense shock. After you set the amount of shock you wish your opponent to receive on the coming trial, the actual trial will begin. You will see the press light and are to depress the reaction time key. At some interval after this, the amber light will go on, and you are to remove your finger as fast as possible. At some interval after the actual response, you will find out whether you were faster or slower than your competitor on that particular trial. The slower person will get a shock of the intensity that was chosen by her competitor. The faster person will not receive the shock which was set for her by the other person.'

'You will be able to tell how much shock the other person had set for you in two ways. First by the intensity of the shock which you actually feel, and second by which of the five red lights on your panel flashes. As you can see, there are five red lights, one for each level of shock. The light on the left indicates the least intense shock, the lights to the right indicate increasing levels of shock, and the light on the right indicates the most intense shock. The white light on the extreme right will flash each time you lose.' 
The slower person on a particular trial will receive the shock and see the light corresponding to the intensity set by the other person before the trial. The faster person will not receive a shock, but will still be able to tell. what the other person had set for her by observing which red light flashes. The maximum shock you can receive, that is the number five, will correspond to the shock level you judged more unpleasant in the preliminary trials. The others will be percentages of this.'

"The following instructions are for the Advisor:

'Each responder in this experiment has an advisor. The responder is to concentrate only on having the fastest reaction time possible. We do not want her to be distracted by other aspects of the experiment. Therefore, your task will be to suggest to the responder which shock button to set. That is, when the set light comes on, you are to advise the responder of what button you think she should press. It is important that you make a suggestion on each trial immediately after the set light comes on. The sound of your voice will trigger a mechanism which permits the trial to continue.'

"To summarize for all subjects:

'When the set light comes on, the advisor is to suggest to the responder the level of shock to set. The responder is then to set one of the shock buttons. When the press light 
goes on, the responder is to depress the reaction time key and hold it down until the amber release light flashes, at which time she is to remove her finger from the reaction key as fast as possible. The slower responder on that trial will receive the shock and see the light corresponding to the level of shock set by the competitors. The faster responder will not receive the shock, but will see the light corresponding to the level his competitors had set for her. It is important that both advisors advise the responders as soon as the set light goes on, and that the responders set a level of shock immediately after being advised and respond to the amber light as fast as possible. 


\section{APPENDIX C}

\section{General Instructions}

On a number of questions, you will be asked to indicate on a 6-point scale the extent to which you feel something is true. The scale will look like this:

$$
11111
$$

You are to circle the line which most represents how you feel.

For example, if you are asked to rate how strong you think the responder is, and you felt she was very strong you would circle the 6 th line:

weak 111111 (1) strong

If you were to rate how strong you are, and you feel you are very weak, you would circle the lst line:

weak (1) 1111,1 strong

If you were to rate the responder's reaction times and you felt that they were moderately fast, you would circle the 5 th line:

$$
\text { very slow } 11,1 \text { (1) very fast }
$$

If you do not understand this rating procedure, please do not hesitate to ask for further explanation. 


\section{APPENDIX C (Cont.)}

In terms of this brief encounter, please rate the responder on a 6 -point scale on the following characteristics:

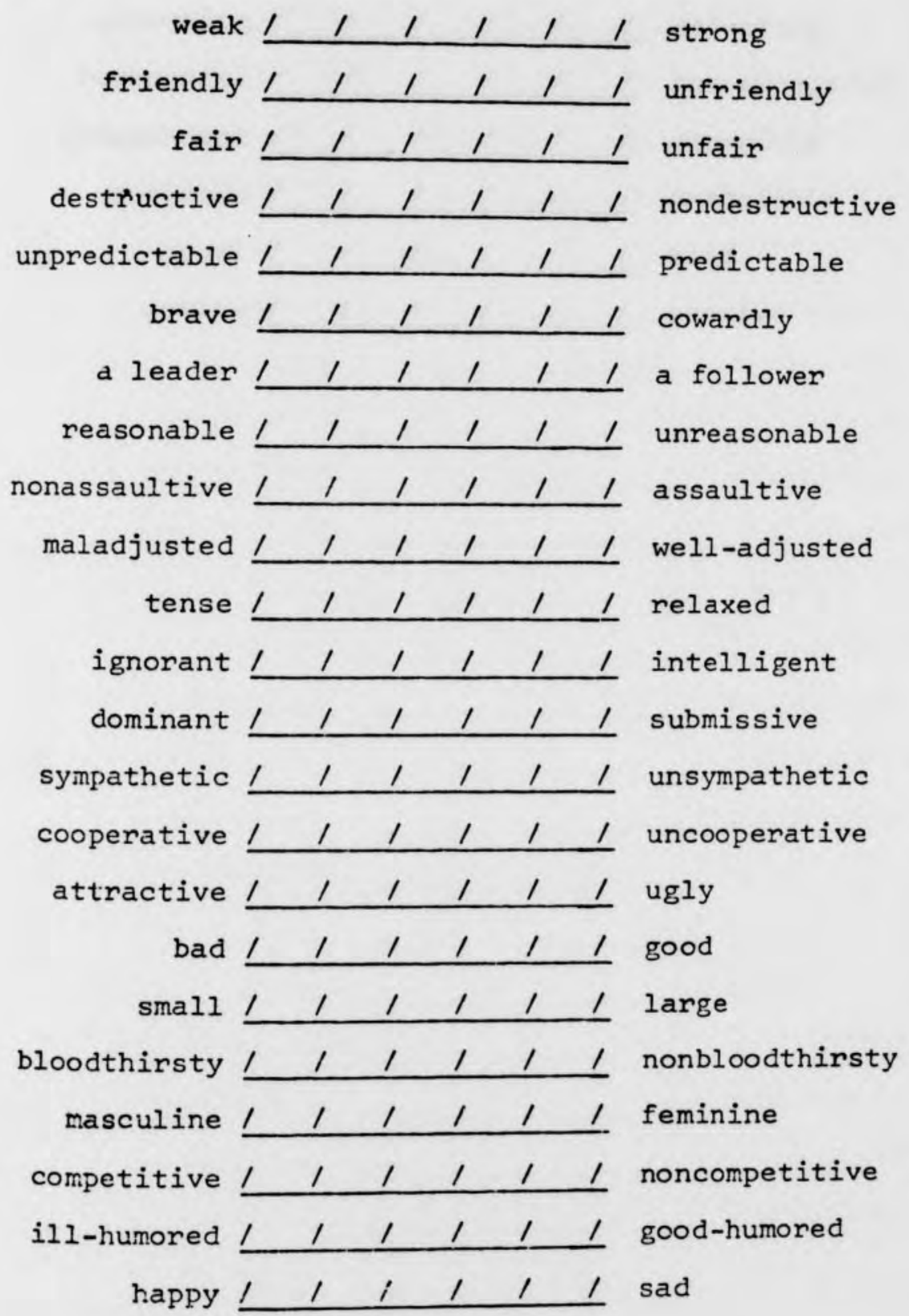




\section{APPENDIX C (Cont.)}

\begin{tabular}{|c|c|c|c|c|c|c|c|}
\hline honest & 1 & 1 & 1 & 1 & 1 & 1 & deceitful \\
\hline aggressive & 1 & 1 & 1 & 1 & 1 & 1 & nonaggressive \\
\hline accepting & 1 & 1 & 1 & 1 & 1 & 1 & rejecting \\
\hline revengeful & 1 & 1 & 1 & 1 & 1 & 1 & nonrevengeful \\
\hline independent & 1 & 1 & 1 & 1 & 1 & 1 & dependent \\
\hline sociable & 1 & 1 & 1 & 1 & 1 & 1 & unsociable \\
\hline cruel & 1 & 1 & 1 & 1 & 1 & 1 & kind \\
\hline active & 1 & 1 & 1 & 1 & 1 & 1 & passive \\
\hline
\end{tabular}




\section{APPENDIX C (Cont.)}

Please rate yourself as you felt at the end of the experiment on a 6-point scale on the following characteristics:

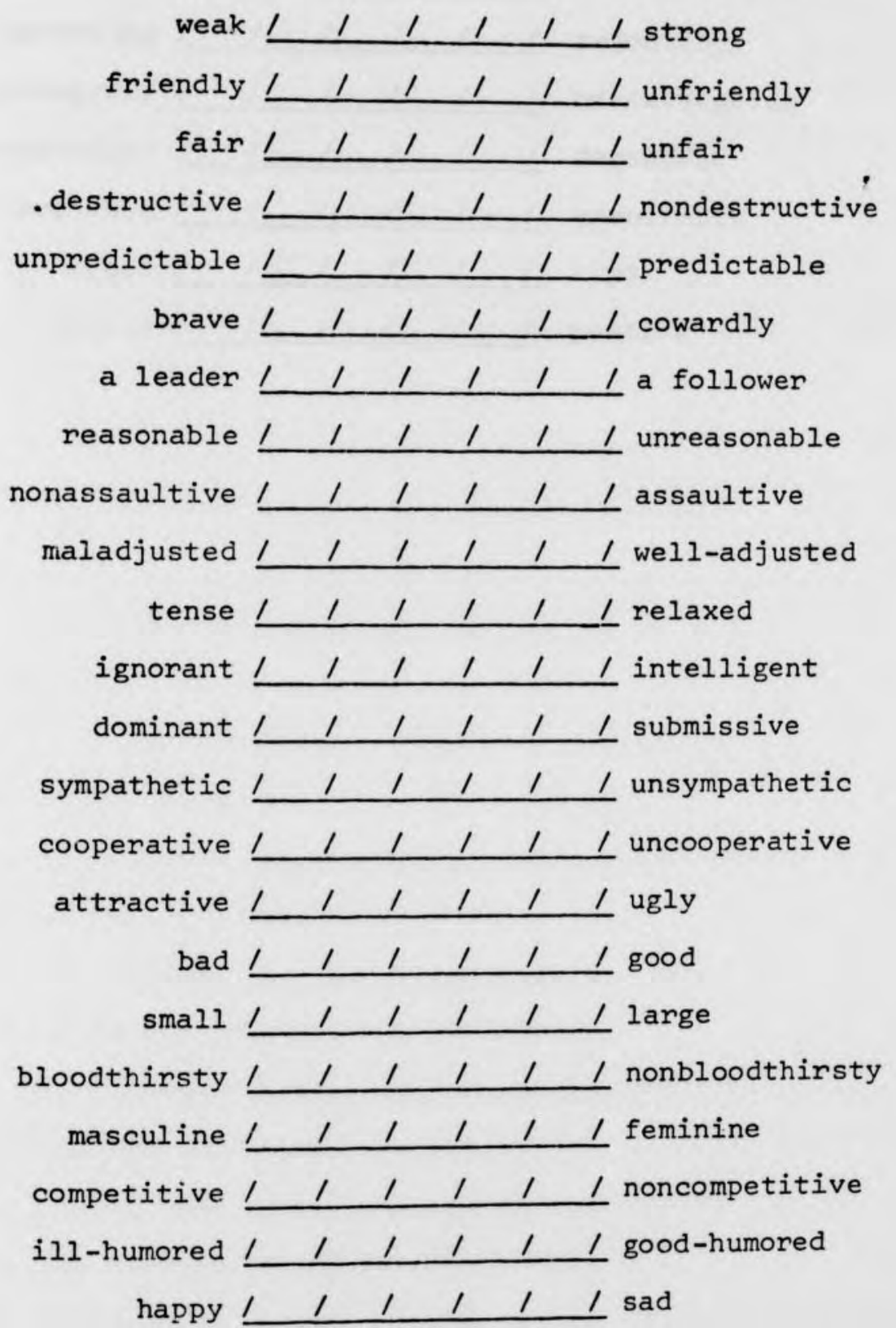


APPENDIX C (Cont.)

\begin{tabular}{|c|c|c|c|c|c|c|c|}
\hline honest & 1 & 1 & 1 & 1 & 1 & 1 & deceitful \\
\hline aggressive & 1 & 1 & 1 & 1 & 1 & 1 & nonaggressive \\
\hline accepting & 1 & 1 & 1 & 1 & 1 & 1 & rejecting \\
\hline revengeful & 1 & 1 & 1 & 1 & 1 & I & nonrevengeful \\
\hline independent & 1 & 1 & 1 & 1 & 1 & 1 & dependent \\
\hline sociable & 1 & 1 & 1 & 1 & 1 & 1 & unsociable \\
\hline cruel & 1 & 1 & 1 & 1 & 1 & 1 & kind \\
\hline active & 1 & 1 & 1 & 1 & 1 & 1 & passive \\
\hline
\end{tabular}




\section{APPENDIX C (Cont.)}

Please describe what type of opponent your responder was competing with.

Do you believe your responder would have had slower reaction times if you had not been present?

please check one.

yes

no

Rate to what extent you think the following factors influenced the responder's reaction times, i.e. made his reaction time faster or slower:

Winning:

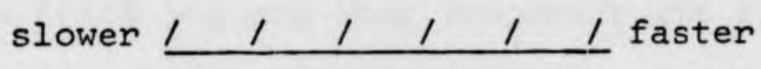

Losing:

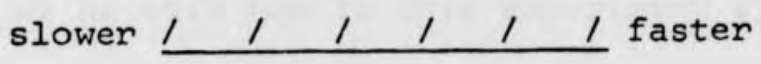

Receiving a high shock:

slower $1 / 1,1 /$ faster

Receiving a low shock:

slower $1 / 1 / 1 /$ faster

Your not having on a shock electrode:

slower $1 / 1,1 /$ faster

* Your setting "restart" on the error panel:

slower $1,1,1$, faster

"Your setting "proceed" on the error panel:

slower $1,1,1$, faster

How effective an advisor do you think you were? very effective $, 1,1,1$, very ineffective 


\section{APPENDIX C (Cont.)}

If you were to be in this experiment again, which would you prefer to be?

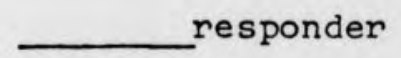
advisor

Did the shocks seem to bother the responder?

$$
\text { yes, a great deal }|,|, \mid, \text { no, not at all }
$$

Did it bother you to watch the responder receive a shock? yes, a great deal $|/|, \mid /$ no, not at all

Rate the painfulness of the shocks you received.

very painful $, 1,1,1$ not at all painful

How well do you think you and your responder got along?

$$
\text { very well } 1 /, 1,1 \text { not at all well }
$$

Would you like to be with her in this experiment again?

$$
\text { very much } 1,1,1, \text { not at all }
$$

Did you enjoy this experiment?

$$
\text { yes, a great deal } 1,1,1, \text { no, not at all }
$$

Briefly describe the strategy you used in suggesting which shock intensities ought to be set.

* Describe the situations when you set the "restart" button on the error panel. 


\section{APPENDIX C (Cont.)}

Did you know or hear anything about this experiment? Explain.

THANK YOU FOR YOUR COOPERATION

* These items were ommitted for No Veto Subjects. 


\section{APPENDIX D}

TABLE 1

Analysis of Variance Summary Table for Trial One Responses of Part 1

\begin{tabular}{lcccc}
\hline \multicolumn{1}{c}{ Source } & SS & df & MS & F \\
\hline Cooperation & .025 & 1 & .025 & .038 \\
Veto & .625 & 1 & .625 & .950 \\
Cooperation $x$ Veto & .025 & 1 & .025 & .038 \\
Within & 23.700 & 36 & .658 & \\
\end{tabular}


APPENDIX D (Cont.)

TABLE 2

Mean Shock Intensities for Part I Averaged Across Win-Lose

\begin{tabular}{lllll}
\hline \hline & 1 & 2 & Trial Blocks & \\
\hline Cooperation-Veto & 2.20 & 2.52 & 2.80 & 4.45 \\
Cooperation-No Veto & 2.22 & 2.43 & 3.15 & 3.63 \\
Noncooperation-Veto & 2.05 & 2.12 & 2.48 & 2.58 \\
Noncooperation-No Veto & 1.78 & 1.80 & 1.93 & 1.87 \\
\hline \hline
\end{tabular}


APPENDIX D (Cont.)

TABLE 3

Analysis of Variance Summary Table for Suggested

Shock Intensities During Part 1

\begin{tabular}{lrrrr}
\hline \multicolumn{1}{c}{ Source } & SS & df & MS & F \\
\hline Cooperation (C) & 41.766 & 1 & 41.766 & $28.206^{* *}$ \\
Veto (V) & 2.386 & 1 & 2.386 & 1.611 \\
Trial Blocks (B) & 32.955 & 3 & 10.985 & $29.376^{* *}$ \\
Win (W) & .0001 & 1 & .0001 & .001 \\
CV & 6.727 & 1 & 6.727 & $4.543^{*}$ \\
CB & 11.645 & 3 & 3.882 & $10.380^{* *}$ \\
VB & .344 & 3 & .115 & .307 \\
CW & .255 & 1 & .255 & .626 \\
VW & .076 & 1 & .076 & .187 \\
& & & & \\
\hline \hline
\end{tabular}

*p $<.05$

$* * \mathrm{p}<.01$ 
APPENDIX D (Cont.)

TABLE 3 (Cont.)

\begin{tabular}{lrrrr}
\hline \hline & Source & SS & df & MS \\
\hline BW & .069 & 3 & .023 & .112 \\
S(CV) & 53.307 & 36 & 1.481 & \\
CVB & 2.066 & 3 & .689 & 1.842 \\
CVW & .293 & 1 & .293 & .720 \\
CBW & .082 & 3 & .027 & .132 \\
VBW & 1.079 & 3 & .360 & 1.744 \\
SB(CV) & 40.386 & 108 & .374 & .407 \\
SW(CV) & 14.635 & 36 & .142 & .6903 \\
CVBW & .427 & 3 & .206 & \\
SBW(CV) & 22.262 & 108 & & \\
& & &
\end{tabular}




\section{APPENDIX D (Cont.)}

\section{TABLE 4}

Mean Shock Intensities for Trial Block 4 of Part 1 and Trial Block 1 of Part 2

\begin{tabular}{lccc}
\hline \hline & 4 & Trial Blocks & 1 \\
\hline Cooperation - Veto & 3.45 & 3.74 \\
Cooperation - No Veto & 3.63 & 3.90 \\
Noncooperation - Veto & 2.58 & 3.08 \\
Noncooperation - No Veto & 1.86 & 2.13 \\
\hline \hline
\end{tabular}


APPENDIX D (Cont.)

TABLE 5

Analysis of Variance Summary Table for Analysis of Change From Trial Block 4 of Part 1 to Trial Block 1 of Part 2

\begin{tabular}{lcccc}
\hline \multicolumn{1}{c}{ Source } & SS & df & MS & F \\
\hline Cooperation (C) & 63.717 & 1 & 63.717 & $31.158 * *$ \\
Veto (V) & 4.346 & 1 & 4.346 & 2.125 \\
Trial Block (B) & 4.346 & 1 & 4.346 & $9.526 *$ * \\
Win (W) & .055 & 1 & .055 & .113 \\
CV & 10.157 & 1 & 10.157 & $4.907 *$ \\
CB & .118 & 1 & .118 & .258 \\
VB & .159 & 1 & .159 & .350 \\
CW & .086 & 1 & .086 & .175 \\
VW & 1.667 & 1 & 1.667 & 3.406 \\
\hline
\end{tabular}

${ }^{*} \mathrm{p}<.05$

$* * \mathrm{p}<.01$ 
APPENDIX D (Cont.)

TABLE 5 (Cont.)

\begin{tabular}{|c|c|c|c|c|}
\hline Source & Ss & df & MS & $\mathbf{F}$ \\
\hline BW & .117 & 1 & .117 & .526 \\
\hline$s(\mathrm{CV})$ & 73.618 & 36 & 2.045 & \\
\hline CVB & .112 & 1 & .112 & .247 \\
\hline cvw & 1.414 & 1 & 1.414 & 2.890 \\
\hline CBW & .499 & 1 & .499 & 2.238 \\
\hline vBW & .006 & 1 & .006 & .027 \\
\hline $\mathrm{SB}(\mathrm{CV})$ & 16.425 & 36 & .456 & \\
\hline SW(cv) & 17.616 & 36 & .489 & \\
\hline CVBW & .018 & 1 & .018 & .083 \\
\hline SBW(CV) & 8.032 & 36 & .223 & \\
\hline
\end{tabular}


APPENDIX D (Cont.)

TABLE 6

Analysis of Variance Summary Table for Trial One Responses of Part 2

\begin{tabular}{lrrrr}
\hline \hline \multicolumn{1}{c}{ Source } & SS & df & MS & \multicolumn{1}{c}{ F } \\
\hline Cooperation & 6.400 & 1 & 6.400 & $7.530^{* *}$ \\
Veto & .100 & 1 & .100 & .118 \\
Cooperation $\times$ Veto & 2.500 & 1 & 2.500 & 2.940 \\
Within & 30.600 & 36 & .850 & \\
& & & & \\
\hline \hline
\end{tabular}

** $p<.01$ 


\section{APPENDIX D (Cont.)}

TABLE 7

Mean Shock Intensities for Part 2 Averaged Across Win-Lose

\begin{tabular}{lcc}
\hline \hline & 1 & Trial Blocks \\
\hline Cooperation - Veto & 3.74 & 3.58 \\
Cooperation - No Veto & 3.90 & 4.02 \\
Noncooperation - Veto & 3.08 & 3.43 \\
Noncooperation - No Veto & 2.13 & 2.35 \\
\hline
\end{tabular}


APPENDIX D (Cont.)

TABLE 8

Analysis of Variance Summary Table for Shock Intensities Set During Part 2

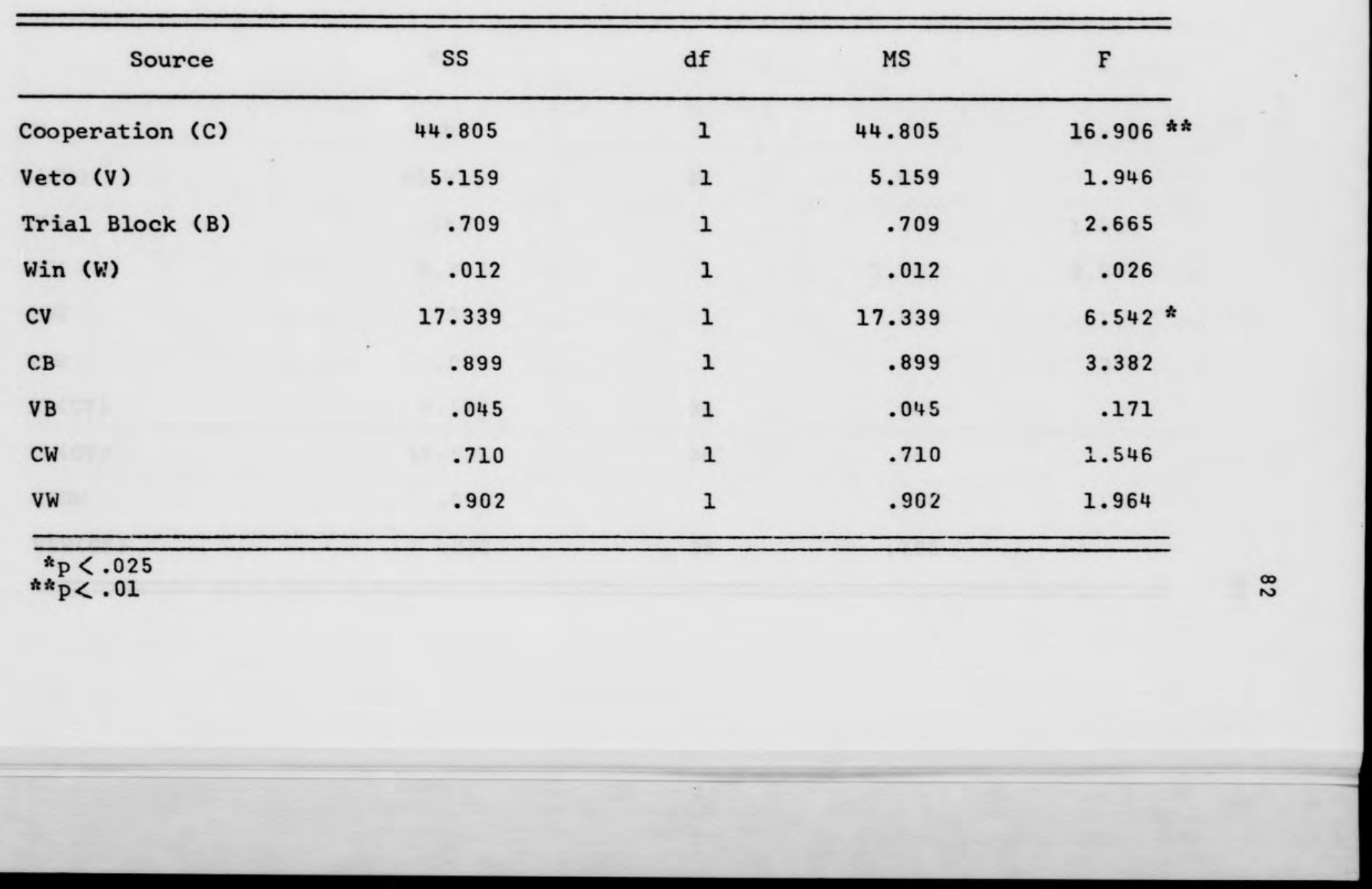


APPENDIX D (Cont.)

Table 8 (Cont.)

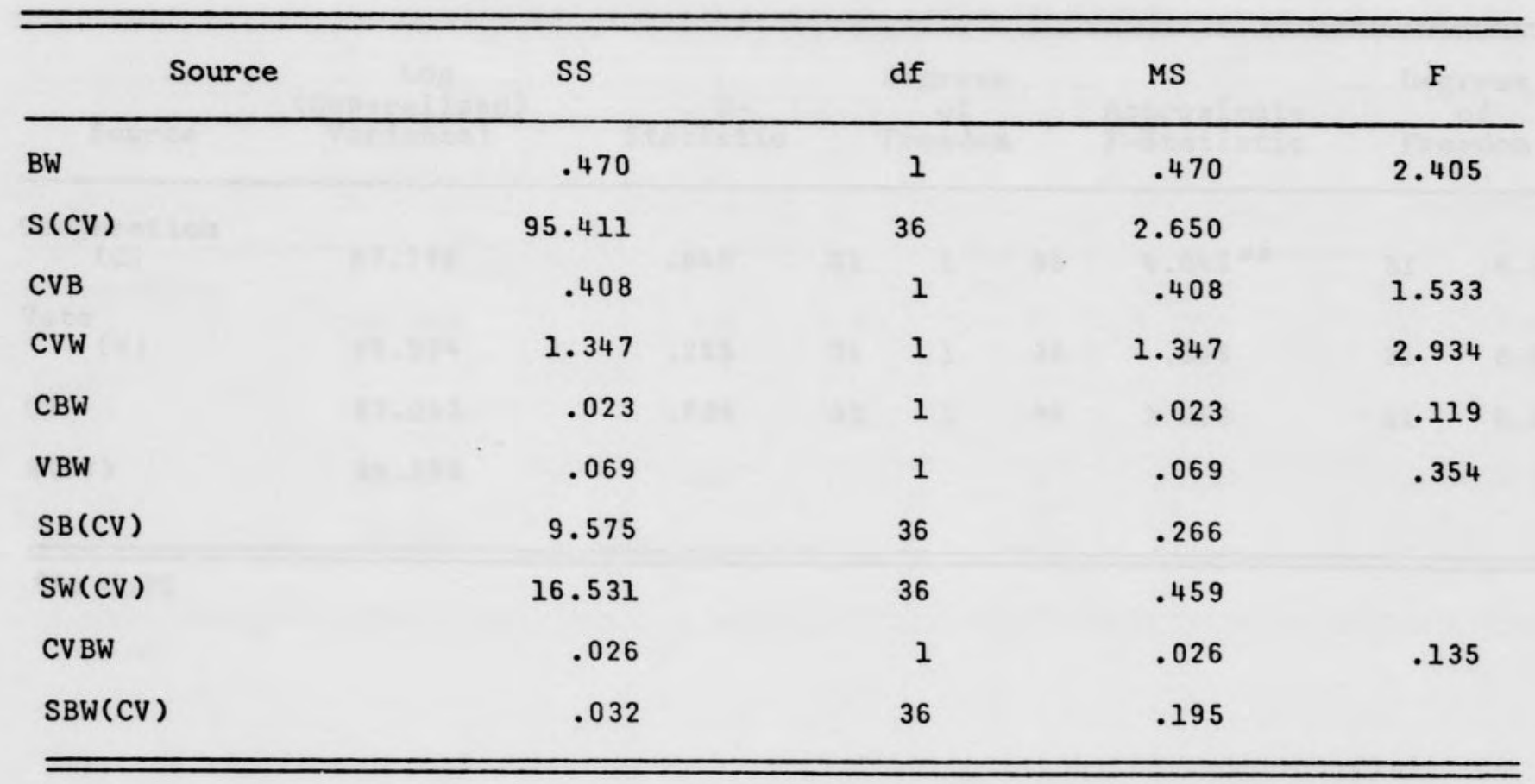




\section{APPENDIX D (Cont.) \\ TABLE 9}

Multivariate Analysis of Variance Summary Table for Ratings of the Responder

\begin{tabular}{|c|c|c|c|c|c|c|c|c|}
\hline \multirow[b]{2}{*}{$\begin{array}{c}\text { Cooperation } \\
\text { (C) }\end{array}$} & \multirow{2}{*}{$\begin{array}{c}\text { Log } \\
\begin{array}{c}\text { (Generalized) } \\
\text { Variance) }\end{array} \\
87.778\end{array}$} & \multirow{2}{*}{$\begin{array}{c}\text { U- } \\
\text { Statistic } \\
.040\end{array}$} & \multicolumn{3}{|c|}{$\begin{array}{c}\text { Degrees } \\
\text { of } \\
\text { Freedom }\end{array}$} & \multirow{2}{*}{$\begin{array}{c}\text { Approximate } \\
\text { F-Statistic } \\
4.646^{*} *\end{array}$} & \multicolumn{2}{|c|}{$\begin{array}{c}\text { Degrees } \\
\text { of } \\
\text { Freedom }\end{array}$} \\
\hline & & & 31 & 1 & 36 & & 31 & 6.00 \\
\hline${ }_{\text {(V) }}^{\text {Veto }}$ & 85.924 & .255 & 31 & 1 & 36 & .565 & 31 & 6.00 \\
\hline $\mathrm{CV}$ & 87.013 & .086 & 31 & 1 & 36 & 2.059 & 31 & 6.00 \\
\hline$S(C V)$ & 84.558 & & & 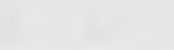 & 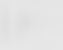 & $\sqrt{2}+x^{2}$ & 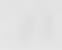 & t \\
\hline
\end{tabular}




\section{APPENDIX D (Cont.)}

TABLE 10

Multivariate Analysis of Variance Summary

Table for Ratings of Self

\begin{tabular}{|c|c|c|c|c|c|c|c|c|}
\hline \multirow[b]{2}{*}{$\begin{array}{l}\text { Cooperation } \\
\text { (C) }\end{array}$} & \multirow{2}{*}{$\begin{array}{c}\text { Log } \\
\begin{array}{c}\text { (Generalized) } \\
\text { Variance) }\end{array} \\
84.846\end{array}$} & \multirow{2}{*}{$\begin{array}{c}\text { U- } \\
\text { Statistic } \\
.202\end{array}$} & \multicolumn{3}{|c|}{$\begin{array}{c}\text { Degrees } \\
\text { of } \\
\text { Freedom }\end{array}$} & \multirow{2}{*}{$\begin{array}{c}\text { Approximate } \\
\text { F-Statistic } \\
.764\end{array}$} & \multicolumn{2}{|c|}{$\begin{array}{c}\text { Degrees } \\
\text { of } \\
\text { Freedom }\end{array}$} \\
\hline & & & 31 & 1 & 36 & & 31 & 6.00 \\
\hline $\begin{array}{l}\text { Veto } \\
\text { (V) }\end{array}$ & 86.055 & .060 & 31 & 1 & 36 & $3.014 \%$ & 31 & 6.00 \\
\hline $\mathrm{CV}$ & 85.564 & .099 & 31 & 1 & 36 & 1.771 & 31 & 6.00 \\
\hline$s(C V)$ & 83.247 & & & & & & & \\
\hline
\end{tabular}


APPENDIX D (Cont.)

TABLE 11

Analysis of Variance Summary Table for Number of Verbal

Comments Made by Subjects During the Experiment

\begin{tabular}{lcccc}
\hline \multicolumn{1}{c}{ Source } & SS & df & MS & F \\
\hline Cooperation & 11.025 & 1 & 11.025 & .028 \\
Veto & 24.025 & 1 & 24.025 & .060 \\
Cooperation x Veto & 469.225 & 1 & 469.225 & 1.173 \\
Within & $14,405.700$ & 36 & 400.158 & \\
\end{tabular}


APPENDIX D (Cont.)

TABLE 12

Analysis of Variance Summary Table for Statements in the "Comments" Category Made During Part 1

\begin{tabular}{lcccc}
\hline \multicolumn{1}{c}{ Source } & SS & df & MS & F \\
\hline Cooperation & .296 & 1 & .2958 & $10.060 * *$ \\
Veto & .100 & 1 & .100 & 3.400 \\
Cooperation x Veto & .056 & 1 & .056 & 1.910 \\
Within & 1.059 & 36 & .029 & \\
\hline \hline : & & & & \\
\hline
\end{tabular}


APPENDIX D (Cont.)

TABLE 13

Analysis of Variance Summary Table for Statements in the "Comments" Category Made During Part 2

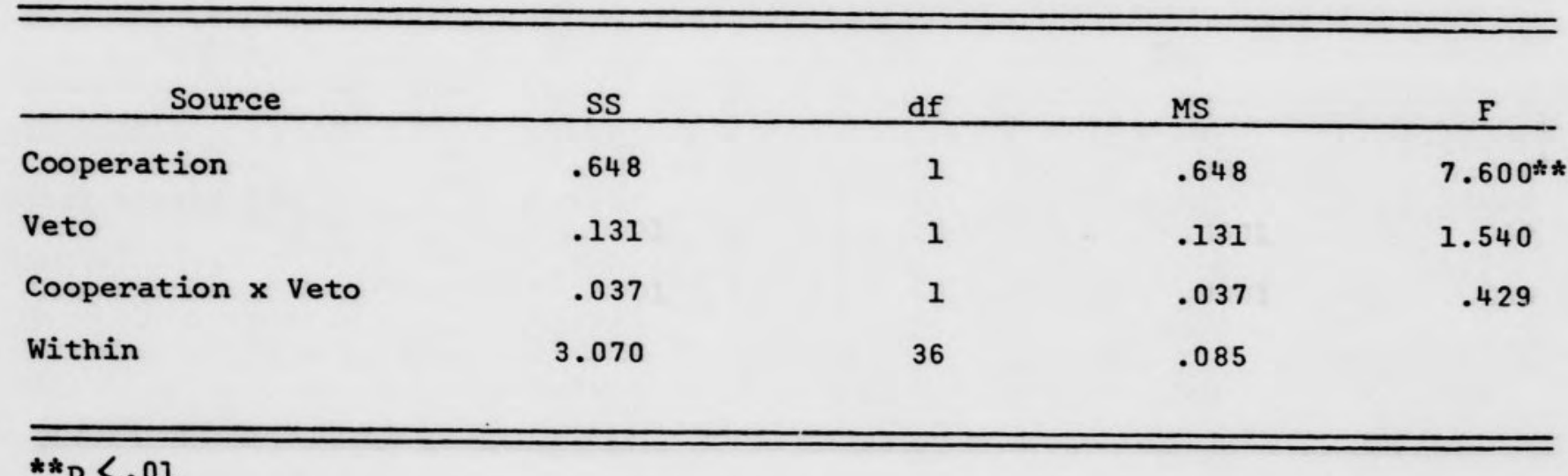

$* *_{\mathrm{p}}<.01$ 


\section{APPENDIX D (Cont.)}

\section{TABLE 14}

Analysis of Variance Summary Table for "Suspicious" Comments Made During

Part 2

\begin{tabular}{lcccr}
\hline \multicolumn{1}{c}{ Source } & SS & df & MS & F \\
\hline Cooperation & .004 & 1 & .004 & $.360^{*}$ \\
Veto & .0001 & 1 & .0001 & .090 \\
Cooperation $x$ Veto & .0001 & 1 & .0001 & .090 \\
Within & .036 & & & \\
\hline
\end{tabular}

${ }^{*} \mathrm{p}<.05$ 


\section{APPENDIX D (Cont.)}

TABLE 15

Analysis of Variance Summary Table for Cooperation-Veto Group as a Function of Subjects, Blocks and Win

\begin{tabular}{lrrrr}
\hline \multicolumn{1}{c}{ Source } & SS & df & MS & \multicolumn{1}{c}{ F } \\
\hline Subjects (S) & 17.758 & 9 & 1.973 & $5.990^{* *}$ \\
Trial Blocks (B) & 16.970 & 3 & 5.657 & $12.929^{* *}$ \\
Win (W) & .446 & 1 & .446 & .818 \\
SB & 11.813 & 27 & .438 & .510 \\
SW & 4.901 & 9 & .545 & .188 \\
BW & .563 & 3 & .329 & \\
SBW & 8.892 & 27 & & \\
\hline \hline k* $<.01$ & & &
\end{tabular}


APPENDIX D (Cont.)

TABLE 16

Analysis of Variance Summary Table for Cooperation-No Veto Group As a Function of Subjects, Blocks and Win

\begin{tabular}{lccrr}
\hline \multicolumn{1}{c}{ Source } & SS & df & MS & F \\
\hline Subjects (S) & 4.623 & 9 & .514 & $2.580 *$ \\
Trial Blocks (B) & 25.561 & 3 & 8.520 & $18.845 * *$ \\
Win (W) & .023 & 1 & .023 & .025 \\
SB & 12.207 & 27 & .452 & .909 \\
SW & 8.179 & 9 & .206 & 1.033 \\
BW & .618 & 3 & .199 \\
SBW & 5.381 & 27 & & \\
\hline
\end{tabular}

$* \mathrm{p}<.05$

$* * \mathrm{p}<.01$ 


\section{APPENDIX D (Cont.)}

TABLE 17

Analysis of Variance Summary Table for Noncooperation-No Veto Group As a Function of Subjects,Blocks and Win

\begin{tabular}{lcccc}
\hline \multicolumn{1}{c}{ Source } & SS & df & MS & F \\
\hline Subjects (S) & 8.707 & 9 & .967 & $7.420^{* 2 *}$ \\
Trial Block (B) & .282 & 3 & .094 & .451 \\
Win (W) & .012 & 1 & .012 & .128 \\
SB & 5.620 & 27 & .208 & .096 \\
SW & .861 & 9 & .109 \\
BW & .328 & 3 & .130 \\
SBW & 3.520 & 27 & & .837 \\
k* $<.01$ & & &
\end{tabular}




\section{APPENDIX D (Cont.)}

TABLE 18

Analysis of Variance Summary Table for Noncooperation-Veto Group As a Function of Subjects, Blocks and Win

\begin{tabular}{|c|c|c|c|c|}
\hline Source & SS & df & MS & $\mathbf{F}$ \\
\hline Subjects (s) & 22.227 & 9 & 2.470 & $14.940 * *$ \\
\hline Trial Blocks (B) & 4.198 & 3 & 1.399 & $3.514^{*}$ \\
\hline Win (W) & .143 & 1 & .143 & 1.852 \\
\hline SB & 10.751 & 27 & .398 & \\
\hline SW & .694 & 9 & .077 & \\
\hline BW & .149 & 3 & .050 & .300 \\
\hline SBW & 4.463 & 27 & .165 & \\
\hline
\end{tabular}




\section{APPENDIX D (Cont.)}

\section{TABLE 19}

Means for Ratings of the Responder By Power, Compliance and Conformity Subjects in the Noncooperation-

Veto Group

\begin{tabular}{|c|c|c|c|}
\hline & \\
\hline & Power & Compliance & Conformity \\
\hline $\begin{array}{l}\text { Unfriendly } \\
\text { Destructive } \\
\text { Assaultive } \\
\text { Bloodthirsty } \\
\text { Ill-humored } \\
\text { Aggressive } \\
\text { Rejecting } \\
\text { Revengeful } \\
\text { Cruel } \\
\text { Competitive } \\
\text { Strong } \\
\text { Leader } \\
\text { Active } \\
\text { Dominant } \\
\text { Large } \\
\text { Masculine } \\
\text { Uncooperative } \\
\text { Independent } \\
\text { Coward } \\
\text { Unfair } \\
\text { Unreasonable } \\
\text { Unsympathetic } \\
\text { Deceitful } \\
\text { Unsociable } \\
\text { Unattractive } \\
\text { Maladjusted } \\
\text { Unintelligent } \\
\text { Unpredictable } \\
\text { Tense } \\
\text { Bad } \\
\text { Unhappy }\end{array}$ & $\begin{array}{l}2.75 \\
1.00 \\
1.50 \\
1.00 \\
3.00 \\
2.50 \\
1.75 \\
2.00 \\
1.00 \\
2.75 \\
3.25 \\
3.00 \\
2.00 \\
2.25 \\
3.00 \\
1.00 \\
2.50 \\
3.25 \\
4.50 \\
2.50 \\
3.25 \\
3.00 \\
1.75 \\
3.50 \\
1.75 \\
1.00 \\
1.75 \\
1.50 \\
4.00 \\
1.75 \\
2.00\end{array}$ & $\begin{array}{l}3.33 \\
1.33 \\
1.00 \\
1.33 \\
2.00 \\
2.00 \\
1.67 \\
1.33 \\
1.67 \\
2.00 \\
3.00 \\
3.33 \\
2.00 \\
3.33 \\
4.33 \\
1.00 \\
3.67 \\
3.33 \\
4.33 \\
3.33 \\
3.33 \\
1.67 \\
2.67 \\
1.67 \\
2.67 \\
3.33 \\
2.67 \\
1.33 \\
2.00 \\
2.00 \\
3.00\end{array}$ & $\begin{array}{l}3.00 \\
1.00 \\
1.00 \\
1.00 \\
1.67 \\
1.33 \\
1.67 \\
1.00 \\
1.33 \\
3.00 \\
4.33 \\
4.00 \\
2.67 \\
4.33 \\
2.67 \\
1.33 \\
1.33 \\
4.00 \\
2.00 \\
1.00 \\
1.33 \\
1.00 \\
1.67 \\
1.67 \\
1.33 \\
1.33 \\
1.67 \\
1.67 \\
1.33 \\
1.33 \\
2.00\end{array}$ \\
\hline
\end{tabular}




\section{APPENDIX D (Cont.)}

TABLE 20

Means for Ratings of Self By Power, Compliance and Conformity Subjects in the Noncooperation-Veto Group

\begin{tabular}{|c|c|c|c|}
\hline & \\
\hline & Power & Compliance & Conformity \\
\hline $\begin{array}{l}\text { Unfriendly } \\
\text { Destructive } \\
\text { Assaultive } \\
\text { Bloodthirsty } \\
\text { Ill-humored } \\
\text { Aggressive } \\
\text { Rejecting } \\
\text { Revengeful } \\
\text { Cruel } \\
\text { Competitive } \\
\text { Strong } \\
\text { Leader } \\
\text { Active } \\
\text { Dominant } \\
\text { Large } \\
\text { Masculine } \\
\text { Uncooperative } \\
\text { Independent } \\
\text { Coward } \\
\text { Unfair } \\
\text { Unreasonable } \\
\text { Unsympathetic } \\
\text { Deceitful } \\
\text { Unsociable } \\
\text { Unattractive } \\
\text { Maladjusted } \\
\text { Unintelligent } \\
\text { Unpredictable } \\
\text { Tense } \\
\text { Bad } \\
\text { Unhappy }\end{array}$ & $\begin{array}{l}1.75 \\
2.50 \\
2.75 \\
1.75 \\
2.00 \\
5.00 \\
2.00 \\
4.75 \\
2.25 \\
5.50 \\
5.00 \\
4.25 \\
4.75 \\
5.25 \\
3.25 \\
1.00 \\
1.75 \\
5.00 \\
1.75 \\
2.00 \\
2.50 \\
2.50 \\
1.00 \\
1.75 \\
2.25 \\
1.75 \\
1.75 \\
3.50 \\
2.00 \\
1.75 \\
1.50\end{array}$ & $\begin{array}{l}2.00 \\
3.33 \\
3.67 \\
2.67 \\
1.67 \\
4.33 \\
2.67 \\
4.33 \\
3.00 \\
4.00 \\
5.00 \\
4.33 \\
5.33 \\
4.67 \\
4.67 \\
3.33 \\
2.33 \\
5.00 \\
2.67 \\
2.67 \\
2.33 \\
2.33 \\
2.33 \\
1.33 \\
3.00 \\
1.67 \\
2.00 \\
2.33 \\
1.67 \\
2.33 \\
1.33\end{array}$ & $\begin{array}{l}1.67 \\
2.00 \\
1.33 \\
1.00 \\
1.67 \\
1.67 \\
2.00 \\
1.33 \\
1.33 \\
2.00 \\
5.33 \\
3.67 \\
3.33 \\
3.67 \\
4.33 \\
1.67 \\
1.33 \\
4.67 \\
3.00 \\
1.33 \\
1.00 \\
1.00 \\
1.67 \\
2.00 \\
2.67 \\
1.33 \\
1.67 \\
2.00 \\
1.00 \\
1.67 \\
1.33\end{array}$ \\
\hline
\end{tabular}




\section{APPENDIX D (Cont.)}

TABLE 21

Mean Ratings for the Last Six Items of the Questionnaire as Given By Power, Compliance and Conformity Subjects in the NoncooperationVeto Group

\begin{tabular}{|c|c|c|c|c|}
\hline & Questions & Power & Compliance & Conformity \\
\hline 1. & $\begin{array}{l}\text { Did the shocks seem to bother } \\
\text { the responder? }\end{array}$ & 2.50 & 4.67 & 3.33 \\
\hline 2. & $\begin{array}{l}\text { Did it bother you to watch the } \\
\text { responder receive a shock? }\end{array}$ & 3.25 & 4.00 & 3.00 \\
\hline 3. & $\begin{array}{l}\text { Rate the painfulness of the } \\
\text { shocks you received. }\end{array}$ & 4.25 & 4.00 & 4.00 \\
\hline 4. & $\begin{array}{c}\text { How well do you think you and } \\
\text { your responder got along? }\end{array}$ & 3.00 & 2.67 & 1.33 \\
\hline 5. & $\begin{array}{l}\text { Would you like to be with her } \\
\text { in this experiment again? }\end{array}$ & 4.25 & 3.33 & 1.67 \\
\hline 6 . & Did you enjoy this experiment? & 2.00 & 3.67 & 2.00 \\
\hline
\end{tabular}

